University of Zurich

Department of Economics

Working Paper Series

ISSN 1664-7041 (print)

ISSN1664-705X(online)

Working Paper No. 41

\title{
The Demand for Social Insurance: Does Culture Matter?
}

Beatrix Brügger, Rafael Lalive, Andreas Steinhauer and Josef Zweimüller October 2011 


\title{
The Demand for Social Insurance Does Culture Matter?*
}

\author{
Beatrix Brügger, University of Lausanne \\ Rafael Lalive, University of Lausanne and CEPR \\ Andreas Steinhauer, University of Zurich \\ Josef Zweimüller, University of Zurich and CEPR
}

June 11, 2010

\begin{abstract}
Can different social groups develop different demands for social insurance of risks to health and work? We study this issue across language groups in Switzerland. Language defines social groups and Swiss language groups are separated by a clear geographic border. Actual levels of social insurance are identical on either side of the within state segments of the language border. We can therefore study the role of culture in shaping the demand for social insurance. Specifically, we contrast at the language border actual voting decisions on country-wide changes to social insurance programs. Key results indicate substantially higher support for expansions of social insurance among residents of Latin-speaking (i.e. French, Italian, or Romansh) border municipalities compared to their German-speaking neighbors in adjacent municipalities. We consider three possible explanations for this finding: informal insurance, ideology, and the media. We find that informal insurance does not vary enough to explain stark differences in social insurance. However, differences in ideology and segmented media markets are potentially important explanatory factors.
\end{abstract}

JEL classification: J21, J64, Z10

Keywords: culture, language, preferences for social insurance, spatial regression discontinuity.

${ }^{*}$ We would like to thank, without implicating, Sam Bowles, Raj Chetty, Lorenz Goette, Mathias Thoenig, H. Peyton Young and seminar participants at University of Lausanne for helpful comments on previous versions of this paper. This project uses data from the Swiss Household Panel (SHP) and we thank Oliver Lipps for support concerning the interpretation and enrichment of the original SHP data. Research funding from the Swiss National Science Foundation (Grant No. 100012-120356/1) is gratefully acknowledged. Addresses: Beatrix Brügger, University of Lausanne, Faculty of Business and Economics, Internef, CH-1015 LausanneDorigny, beatrix.bruegger@unil.ch. Rafael Lalive, University of Lausanne, Faculty of Business and Economics, CH-1015 Lausanne-Dorigny, rafael.lalive@unil.ch. Rafael Lalive is also affiliated with CESifo, IFAU, and IZA. Andreas Steinhauer, University of Zurich, Department of Economics, Mühlebachstrasse 86, CH-8008 Zürich, steinhauer@iew.uzh.ch. Josef Zweimüller, University of Zurich, Department of Economics, Mühlebachstrasse 86, CH-8008 Zürich, zweim@iew.uzh.ch. Josef Zweimüller is also affiliated with CESifo, and IZA. 


\section{Introduction}

I have previously remarked that the customs of the people may be considered as one of the great general causes to which the maintenance of a democratic republic in the United States is attributable. I here use the word customs with the meaning which the ancients attached to the word mores; for I apply it not only to manners properly so called-that is, to what might be termed the habits of the heart-but to the various notions and opinions current among men and to the mass of those ideas which constitute their character of mind. (de Tocqueville, 1899, ch.17)

Should a society insure individuals against economic shocks and, if yes, what is the optimal extent of redistribution associated with government-provided social insurance? These questions are among the most hotly debated economic policy issues. President Obama's plan to introduce universal health insurance in the United States divided the population into two camps. Proponents argue that a society should take responsibility for individuals in need, as market-failures, discrimination, and poverty exclude socially disadvantaged groups from insurance markets. Opponents (the tea party movement in particular) argue against universal insurance because it curtails the freedom of choice, undermines individuals' responsibility for their own fortune and creates negative incentive effects.

The tension between the active role of governments to mitigate market failures and the adverse consequences of over-sized governments are at the heart of every discussion about the proper extent of social insurance provisions. Today, most countries have adopted some form of re-distributive welfare state programs to mitigate the consequences of economic shocks to individuals. However, these institutions differ widely across countries and the differences have been persisting since a long time. While U.S. about $16 \%$ of GDP go to social insurance programs in the U.S., Sweden spends almost twice as much - 29.4\% - on insuring residents against risks to work and health (OECD 2005). Since these economies have reached similar levels of economic development, these stark differences in the role of social insurance suggest that culture plays an important role to explain the differences in actually implemented institutions.

In this paper, we ask whether social groups develop different demands for social insurance of risks to health and work. Answering this question is important for at least three reasons. First, insurance of risks to health and work is key for well-being as both health and work capacity are key components of human capital. Second, there is tremendous variation in terms of actual coverage of these two key risks. For instance, health insurance used to be tied to employment in the US whereas the typical country in the EU offers universal health insurance coverage. Third, democracies decide on social insurance in a political process. It is therefore central to understand the determinants of the demand for social insurance among voters.

We first ask whether the demand for redistribution varies among countries that have reached comparable levels of economic development. The International Social Survey Programme (ISSP) allows us to answer this question. ${ }^{1}$ In 1996, the ISSP was particularly interested in measuring the role of government across its member countries. One survey item referred to the statement

\footnotetext{
${ }^{1}$ The ISSP regularly interviews random samples of residents of countries that are members of the survey programme. Currently, 45 countries participate in the programme including most OECD countries.
} 
Respondents could indicate whether they disagree strongly, disagree, are indifferent, agree, or agree strongly with this statement. Across a range of selected member countries Figure 1 reports the share agreeing or agreeing strongly that government should redistribute income. The figure shows two key results. First, opinions differ enormously across countries on this issue. In the US only about a third of respondents indicated that government should redistribute. In contrast, in France and Spain between 70 and 80 percent of respondents are in favor of redistribution by government. ${ }^{2}$ Second, there is strong within country variation in demand for redistribution in Germany and Switzerland. Alesina and Fuchs-Schündeln (2007) explain differences in demand for redistribution by socialist policies. East Germany adopted socialist policies between 1945 and 1990 whereas West Germany did not. But note that attitudes towards government-redistribution within Switzerland are of an order of magnitude that compares well to variation across OECD countries. In the Latin (French and Italian)-speaking parts of Switzerland 68.9 percent of respondents indicate that they favor government redistribution. In the German-speaking part only 46.0 percent indicate such a preference.

Figure 1: Government should reduce income differences;

\section{World Ranking}

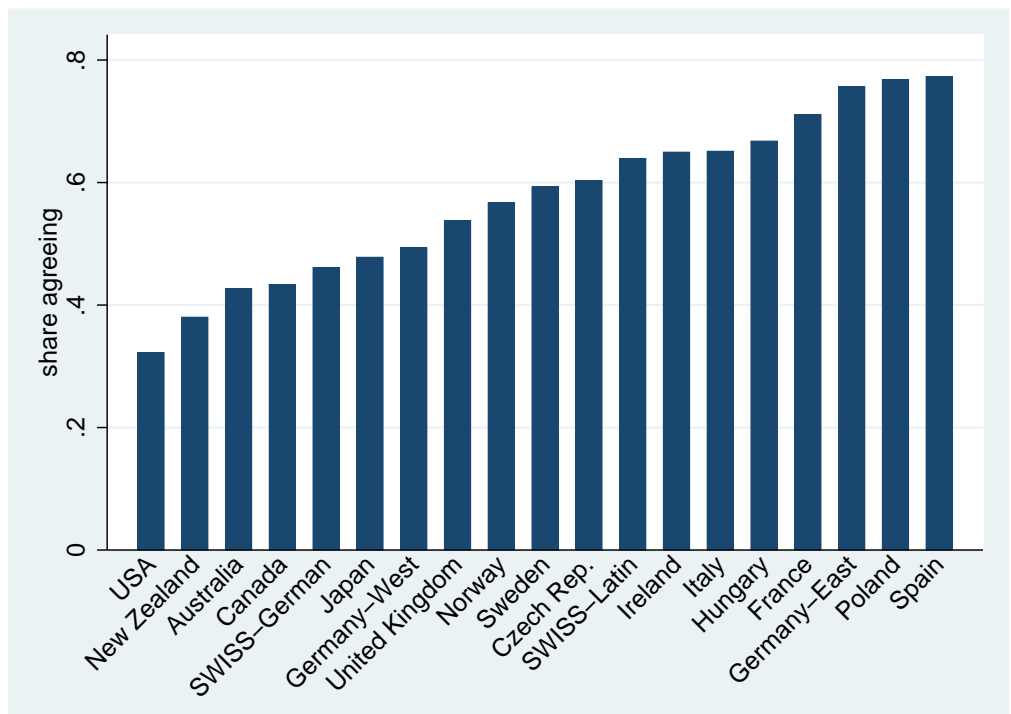

Notes: Reported is the share agreeing or strongly agreeing with the statement.

Source: ISSP 1996.

Figure 1 suggests that there are strong differences in the demand for redistribution across countries but also across regions within countries. We seek to understand whether the demand for social coverage of risk can vary across social groups ceteris paribus. As cited above, Alexis de Tocqueville took a clear stand on this question. But to what extent does his conjecture hold up to formal empirical testing? We argue that the border between two language

\footnotetext{
${ }^{2}$ The clustering of countries corresponds to our expectations. In Anglo-Saxon countries (US, New Zealand, Australia, and Canada) the demand for redistribution is weak whereas in former communist countries (Poland and Hungary) and continental/Southern European countries (Italy, France, and Spain) the demand for redistribution is very strong. Note that these countries all speak languages that are direct descendants of ancient Latin as well.
} 
groups in Switzerland - the "Latin-speaking" (i.e. French, Italian, or Romansh) group and the "German-speaking" group - provides causal evidence on cultural variation in the demand for social insurance. Latin language groups are minorities within Switzerland, comprising roughly 25 percent of the native Swiss population and entertain strong links with their neighbors Italy and France speaking the same language. In contrast, the Swiss German language group comprises roughly 75 percent of the native Swiss population and entertains much weaker ties to the large neighbor speaking the same language, Germany. Swiss language areas appear to be associated with specific cultural traits that create an important cultural gap within the country. ${ }^{3}$ German Swiss individuals are known for their commitment to work hard, to be punctual, and to focus on individual responsibility. In contrast, Latin Swiss, historically being the suppressed minority within the country, tend to rely much more on the role of the state and favor income redistribution.

In this paper we argue that the cultural diversity within Switzerland together with its particular political institutions allows us to shed light on the role of culture to explain the demand for redistributive social insurance. First, the Swiss case allows us to study cultural differences by comparing the behavior of language groups. A common language is a mechanism that lets norms and values persist within a group even when there is a geographically close other group that holds quite different norms and values. The native language that an individual is exposed to during childhood and adolescence is likely to be an important predictor of the individual's values during adulthood to the extent that values are transmitted vertically. Language is central to any type of social interaction. Language is also central to mixing. Novembre et al. (2008) find that genetic markers differ more strongly between people living in Latin Swiss areas and the German Swiss area than within those regions. Hence the native language is also a good predictor of values to the extent that values are transmitted horizontally. Language serves as a medium by which attitudes, values, and beliefs are transmitted from one generation to the next. Language is central to the spreading of beliefs and norms and determines an individual's social identity ${ }^{4}$ The language barrier is a cultural barrier. ${ }^{5}$

A second reason why Switzerland is interesting is the fact that language groups are located in separate regions but these regions are geographically close and have a sharp geographic border. Within a distance of 5 kilometers, the fraction of Latin-speaking Swiss residents falls from more than 90 percent to less than 5 percent (and vice versa for German native speakers). Yet there is no associated change in geography and politics at this language border as the main geographical border, the Alps, are in East-West direction, while the language border mainly runs in NorthSouth direction, and large parts of the language border run within Swiss states (cantons). This is important since most policies in Switzerland are set at the cantonal (rather than the federal) level. Within-canton contrasts on either side of the border measure to what extent social groups

\footnotetext{
${ }^{3}$ The cultural gap is associated with a geographical language border and is called Röstigraben, referring to Rösti, a popular potato-dish in the German-speaking (but not in the Latin-speaking) part of the country. For an interesting recent contribution that describes the origins and persistence of this cultural gap, see Bc̈hi (2000).

${ }^{4}$ Trépanier (1991) discusses the forging of the Cajun regional identity in French Louisiana. Aspachs-Bracons et al. (2007) find that language shapes identity in Spanish regions.

${ }^{5}$ The introductory quote by de Tocqueville (1899) provides an excellent definition of culture. Guiso et al. (2006) define culture as ...those customary beliefs and values that ethnic, religious, and social groups transmit fairly unchanged from generation to generation.
} 
demand different levels of social insurance even if they face identical levels of actual insurance.

Third, a particularly distinguishing feature of the Swiss society is the high importance of direct democracy. National referenda are held on a regular basis where citizens vote over all kinds of issues. Voting results on these national referenda are informative on the regional distribution of citizens' attitudes and values. This is because voting results are available on a community basis and, on average, communities are small and geographically close to each other. Hence voting results help to understand how cultural differences affect the demand for social insurance within narrowly defined geographic areas.

From an econometric point of view, our empirical strategy is a spatial regression discontinuity design. We exploit the fact that the dominant language changes abruptly within a very small geographic distance. Hence distance to the language border (negative on the German side, positive on the Latin side) can serve as the running variable. When this variable takes the value zero, our measure of culture changes discontinuously. The key identifying assumption is that factors other than culture - that potentially determine the demand for social insurance - do not change discontinuously at the language border. This assumption is plausible for the segments of the language border that run through cantons. Cantons have much discretion in setting legal rules. But the within canton segments allow us to adopt a within canton estimation strategy, i.e. to add canton fixed effects. This means that observed differences in voting on social insurance at the language border reflect differences in this demand generated by differences in culture.

Our empirical analysis comes in three parts. First, we document the role of culture for preferences for social insurance using data from the World Values Survey (WVS) and the International Social Survey Programme (ISSP). We first show that significant differences between the Latin Swiss and the German Swiss population in attitudes and norms related to government-provided social insurance exist. These differences are large also compared with evidence from other countries. For instance, we find that the Latin-German gap within Switzerland is almost as large as the gap between Sweden and Canada. Furthermore, these differences turn out to be quite strong even after controlling in detail for the respondents' individual characteristics. For instance, the question "should government reduce income differences"shows a raw Latin-German gap (percentage yes Latin minus percentage yes German) of 22.9 percentage points, which remains as high as 18.9 percentage points after controlling for a variety of community characteristics. We document that significant differences show up for a variety of other WVS- and ISSP-questions that are related to government-provided social insurance.

Second, our main empirical analysis is based on community-data from voting behavior in Swiss national referenda. To concentrate on government-provided social insurance, we consider national referenda since 1980 in which the Swiss population had to vote on one of the following issues: (i) old-age insurance; (ii) maternity insurance; (iii) unemployment insurance; and (iv) health insurance. There were several referenda on these issues. To provide empirical evidence for a role of culture on the demand for social insurance we look at the gap in voting outcomes at the language border. We consistently find a significant Latin-German gap in the demand for government-provided social insurance, that is both quite stable over time and significant across the various social insurance programmes. Language-group-differences in voting are particularly striking with respect to old-age insurance and maternity insurance, but they are also sizeable and significant with respect to unemployment insurance and health insurance. 
Third, we look for potential channels by which cultural background translates into higher support for redistributive social insurance on the Latin side of the language border. One straightforward channel could be that German-speaking Swiss citizens have stronger social networks (family ties, friends, club memberships) that provide them informal insurance as a substitute to formal state-provided insurance. Using data from the Swiss Household Panel we do not find strong support for weaker social networks in Latin-speaking Switzerland. A second possible channel are systematic differences in ideology. We find that Latin speakers are less likely to believe that hard work pays off; and perceive that they enjoy less freedom and control over their lives than German speakers. Hence our results are consistent with Bénabou and Tirole (2006), who argue that weak beliefs in a "just world" increases the demand for redistribution and social insurance. Finally we look at media exposure across langauge regions and find very strong segmentation of media markets by language regions. This may explain the lack of convergence in beliefs among social groups that live under similar institutional arrangements. Interestingly, the pattern of results we find for Switzerland is consistent with de Tocqueville (1899)'s conjecture that culture is a first order explanation for why democracy works so differently in the US compared to Europe cited in the beginning of the introduction.

Previous papers investigating the role of culture for the support of redistributive policies are Luttmer and Singhal (2008) and Alesina and Giuliano (2009), who document a strong impact on immigrants' preferences for redistribution by the corresponding average preferences of origin countries that is persistent across generations. ${ }^{6}$ Alesina and Fuchs-Schündeln (2007) find that after the German reunification East Germans that lived under a Communist regime have consistently stronger preferences for redistribution than their West German neighbors and suggest that indoctrination of pro-state behavior during the Communist regime could have caused the differences in preferences and that the political regime in place can shape individuals preferences. Bénabou and Tirole (2006) present a model where differences in political ideology and support for redistribution arises as a results of differences in believes in a "just world" where effort pays off. Alesina and Angeletos (2005) present a closely related model along with empirical results. Alesina and Glaeser (2004) investigate US and European style welfare systems and argue the belief that "hard work brings success" dominates in the former and "success is a matter of luck and connections" is more prevalent in the latter which may be due to the high political influence of trade unions in Europe. Fong (2001) shows empirically that individuals who prefer more redistribution also think that poverty is caused by circumstances beyond individuals' control. Algan and Cahuc (2009) argue that cultural differences can explain why some countries implement different mixes of employment protection and unemployment insurance. Further related papers are Corneo (2001) who finds that moral values and ideologic principles partly explain differences in preferences for redistribution in Germany and the US. ${ }^{7}$

\footnotetext{
${ }^{6}$ The literature on the role of culture in economic outcomes derives from a more general discussion of the role of culture in the evolutionary process. Boyd and Richerson (1985) is the seminal contribution in evolutionary biology on cultural transmission. See also the more recent work by Bisin and Verdier (2000) who introduce rational choice into the cultural transmission framework.

${ }^{7}$ Three additional strands of the literature are strongly related. The first strand discusses the role of institutions in shaping preferences. Bowles (1998); Bowles and Polanía Reyes (2009) provide surveys of the effects of incentives, markets, and institutions on preferences. The second strand discusses the role of norms for central economic decisions. Young and Burke (2001) discuss cropsharing contract choice in Illinois and show that contracts are
} 
Our paper contributes to this literature in three different ways. First, it uses a novel empirical strategy to assess the impact of culture on differences in economic/political outcomes: the spatial regression discontinuity design. We think that this empirical strategy is quite fruitful in cases where culture changes within narrowly defined geographic areas. Second, our paper studies the role of culture for an outcome that has not received a lot of attention so far: support for government-provided social insurance. While the popularity (and actual implementation) of these programmes vary widely across countries, not much is known about whether these differences may be driven by cultural factors. Third, we provide empirical evidence for cultureeffects by exploiting differences across language groups. The example of Switzerland, with its cultural diversity and particular institutions, provides us with a nice laboratory to assess the determinants of culture on outcomes.

The remainder of this paper is organized as follows. The next section 2 provides relevant background on Swiss language regions and social insurance of risks to health and work in Switzerland. Section 3 discusses identification and estimation of the effect of being socialized in the Swiss Latin culture as opposed to being socialized in the Swiss German culture on voting decisions. Section 4 presents and interprets the main results. Section 5 discusses two key competing explanations of the observed discontinuities in voting, namely informal insurance and ideologies. Section 6 summarizes the key findings and discusses the most important implications of these findings.

\section{Background}

This section offers the key background on Swiss language regions. We also briefly describe the voting procedure and social insurance that is currently in place in Switzerland. The section then discusses first key evidence on different attitudes towards the role of government across language groups.

\subsection{Languages in Switzerland}

Switzerland has four official languages. The North East of Switzerland speaks Swiss German, the West speaks French, the South East speaks Italian, and some parts of the East speak Romansh. According to the population census 2000, 72.5 percent of Swiss citizens speak German, 21.0 percent speak French, 4.3 percent speak Italian, 0.6 percent speak Romansh and 1.6 percent speak other languages (Lüdi and Werlen, 2005). ${ }^{8}$ The Swiss multilingual situation is supported

surprisingly insensitive to soil quality. They can explain this finding by assuming that producers conform to contract choice of their neighbors. See also Burke and Young (2010) for an overview of the role of social norms for economic decisions. See also Clark (2003); Stutzer and Lalive (2004) who discuss the role of social norms in unemployment. The third strand discusses the role of social capital in shaping political and economic outcomes. Leonardi et al. (1993) and Putnam (2000) provide descriptive accounts of how measures of participation in local social life is correlated with political participation and other measures of cooperation such as trust. Durlauf and Fafchamps (2005a) discuss the role of social capital in economics and the problems associated with measuring its effects on cooperation, trust, and economic growth.

${ }^{8}$ The numbers in the text refer to the Swiss citizens. Roughly 20 percent of residents are immigrants of which 62.3 percent speak either German, French, Italian or Romansh and 37.7 percent have some other first language. Romansh is one of the Rhaeto-Romance languages, believed to have descended from the Vulgar Latin variety 
by its education system. Children learn to speak another "Swiss" language as their second language. ${ }^{9}$ The empirical analysis contrasts the regions speaking languages derived from Latin - French, Italian, Romansh - with the regions speaking German. Figure 2 displays a map of Switzerland shaded according to the language spoken by a majority of each region's residents. Areas with light shading are communities with majority German speaking populations. Areas with dark shading are those with a majority speaking either French, Italian, or Romansh. Note that dark lines separate the 26 Swiss cantons, i.e. states.

Figure 2: Majority language, by community

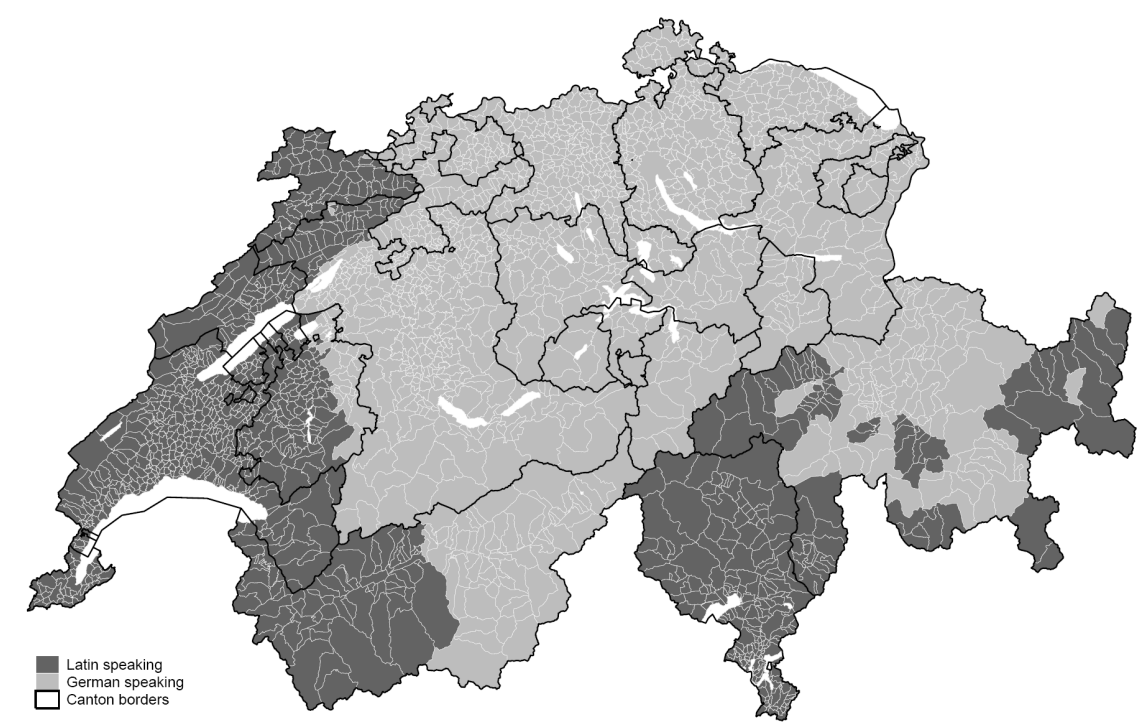

Notes: Language regions in Switzerland by the Swiss population census 2000.

Source: Swiss population census 2000, Federal Statistical Office, Neuchatel. Geographical data from Swisstopo, Federal Office of Topography.

There are two key features of the Swiss language barrier. First, important parts of the language border are no geographical barrier. The language border runs from North to South (the border between French-speaking and German-speaking regions) whereas the main geographical barrier, the Alps, are in East-West direction. This fact, together with an efficient (public) transportation system, implies that transport costs within language regions are similar to transport costs across language regions (conditional on distance). Second, important segments of the language border do not coincide with borders between cantons (dark lines). This means that people living within one of the four multi-lingual cantons but on different sides of the language border face the same regional set of policies and institutions but they belong to different language groups.

Historically, Switzerland was founded by the German-speaking cantons Schwyz, Uri and Nidwalden, located in the center of the country and was successively enlarged by the entrance of Berne, Zurich, Lucerne and other cities of the German-speaking part. Until the French

spoken by Roman era occupiers of the region, and, as such, is closely related to French, Occitan and North Italian.

${ }^{9}$ This translates into good command of the languages spoken in other parts of the country. Around $73 \%$ of the inhabitants of the French speaking regions of Switzerland are able to speak one additional language of the country. The corresponding number is $92 \%$ for the inhabitants of the Italian speaking regions, and $85 \%$ for the inhabitants of the German speaking regions (see Werlen (2008)). 
invasion at the turn of the 19th century large parts of French Switzerland were ruled by the German-speaking elites of Berne and Fribourg. In 1848, the new constitution with 26 cantons was established. Four cantons are French-speaking, one is Italian-speaking, three are bilingual (French / German) cantons (Berne, Valais, and Fribourg), one canton - Graubünden - is officially trilingual (German, Rhaeto-Romansh, and Italian) and the remaining seventeen are Germanspeaking cantons. ${ }^{10}$

\subsection{Social insurance programmes in Switzerland}

It is important to understand what social insurance programmes do exist to understand the demand for more social insurance. Switzerland offers mandatory programmes to insure individuals against major shocks to the two central components of human capital - shocks to health and shocks to earnings. In our empirical analysis below, we will focus on the following insurance programmes which characterize most modern welfare states and which are mandatory for all individuals in Switzerland:

A. Health insurance The Swiss health insurance system is mandatory for all employees. It is highly regulated and offers the same exhaustive list of basic treatments for everyone. Insurance is provided by private insurance companies. Insurance premia vary locally. The quality of health services is very good but also expensive. Switzerland ranks after the US and France among OECD countries with the highest health expenditures (See, OECD Health Data 2009, OECD (http://www.oecd.org/health/healthdata).

B. Social Security Swiss old-age social security is characterized by a three-pillar system. The first pillar is a pay-as-you-go social security system in which individuals pay contributions during their lifetimes and get benefits as soon as they reach the statutory pension age (65 for men, 62 for women). The first pillar has a strong redistributive dimension as benefits are capped but contributions are a tax on labor income. The second pillar is a mandatory funded system. Employer and employees pay into a pension fund which retirees can access once they reach the retirement age. Finally, the third pillar are voluntary pension savings accounts which are tax-deductible.

C. Unemployment insurance The Swiss unemployment insurance system is among the most generous in OECD countries. Depending on age, it grants up to 2 years of unemployment benefits and, depending on family circumstances, a replacement rate of 70-80 percent of previous

\footnotetext{
${ }^{10}$ Multilingual cantons exist for historical reasons. The current border of the canton of Valais traces the ancient border of the Roman catholic diocese of Sion. The current border of the cantons Fribourg and Berne traces the lands acquired by their capitals Fribourg and Berne. The border of the canton of Graubünden traces the borders of the ancient Roman province of Rhaetia. The language border has been very stable since the 20th century. Swiss Linguists argue that the 19th century abolishment of dialect in the French speaking part of Switzerland contributed to stability. The German speaking parts of Switzerland were also keen on abolishing dialects during the late 19th and early 20th century. During WWII, however, German speaking Swiss differentiated themselves from Nazi Germany by using dialect. This explains the current situation with the French speaking parts of Switzerland using standard French whereas German speaking parts of Switzerland still use dialect. See ?? for a historical account of the language border.
} 
income. The system is designed to prevent long-term unemployment by a strong emphasis on active labor market policies. Individuals are obliged to participate in such programs. Noncompliance with benefit rules and/or refusal to participate in active labor market policies lead to benefit sanctions.

D. Maternity insurance Family policies are much less generous in Switzerland than in many other OECD countries. Before 2005 no mandatory maternity/parental leave system existed. Since the 1950s several referenda were held about the implementation of such a system but all referenda failed. The referendum in 2004 was approved by the population. It grants mothers a 12 -week job protection associated with full pay. Large private companies typically offer supplementary parental leave provisions.

\subsection{Demand for redistribution across language regions}

Table 1 reports differences across language groups regarding support of redistribution and/or government-provided social insurance programs using ISSP 1996 and world values survey (WVS) data for 1996. All results focus on Swiss nationals whose interview language is either German, French, or Italian so that language serves as a proxy for cultural background. ${ }^{11}$ Table 1 reports agreement for each particular item separately in the Latin-speaking and the German-speaking part part. The second-to-last column reports the raw difference and the last column shows the coefficient of the Latin dummy in a linear regression that includes education, age, gender, and canton fixed-effects as control variables. ${ }^{12}$ Hence the Latin coefficient in the last column of Table 1 reports the within canton difference in support for redistribution and social insurance. Since individuals within cantons are subject to identical institutional arrangements, this differential is not driven by differences in policies.

Results suggest that agreement to the statement "should government reduce income differences" remains 18 percentage points higher in Latin-speaking Switzerland even when we control for background characteristics and canton fixed-effects. Very similar patterns emerge with respect to questions whether governments should create and provide jobs; help the unemployed; and social spending. In all issues, Latin Swiss residents support a more active government providing more social insurance and redistribution. While the gap differs by survey item, a significant Latin-gap remains in all cases.

Table 1 also provides evidence of two questions in the World Value Survey concerning the role of government versus

the role of the individual: (i) Should individuals take more responsibility vs. should government take more responsibility and (ii) Is it justifiable to claim government benefits to which you are not entitled?. Both questions are answered on a scale from 1 to 10. It turns out that

\footnotetext{
${ }^{11}$ We take interview language as a proxy for the native language of the respondent. We have no information that would allow us to calculate reliability of this proxy. Yet note that survey institutes typically choose interview language to match native language of the majority of a respondents municipality of residence and - with few exceptions - municipalities are segregated with respect to language. This suggests that interview language is a fairly good proxy for native language.

${ }^{12}$ According to the Swiss political scientists Bonoli and Häusermann (2009), education, age, and gender are thought to be the most important dividing lines in votes on redistribution. Indeed, they find age to be the most important factor explaining voting patterns in exit polls.
} 


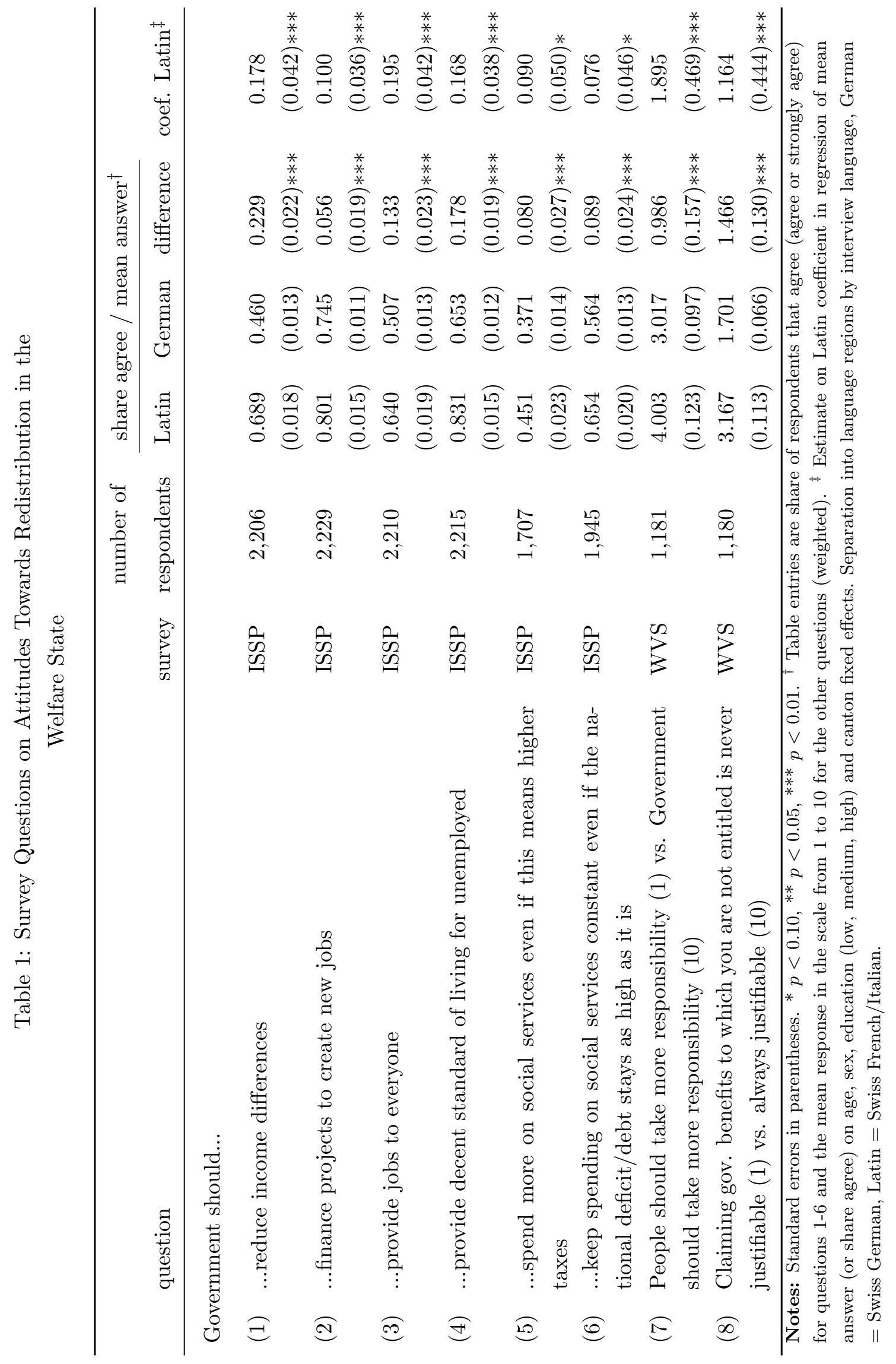


the average government-responsibility score of Latin Swiss respondents is 1.9 points (!) higher than the score of Swiss-German speakers. The difference is also quite striking in the benefitclaim score where the Latin-gap is as large as 1.2 points even after controlling for background characteristics and canton fixed-effects. ${ }^{13}$ In sum, the evidence of Table 1 is consistent with the hypothesis of a potentially important impact of culture on the demand for redistributive social insurance.

\section{Identification and Estimation}

This section discusses the empirical challenges to identifying the pure effect of being a member of a language group on the demand for social insurance. The section then discusses the empirical framework adopted in this paper - a spatial regression discontinuity approach.

\subsection{Identification}

This paper asks whether different language groups develop different attitudes towards social insurance, ceteris paribus. This effect lies at the heart of all discussions surrounding culture. It is useful to introduce notation used in the treatment effects literature to clarify the parameter of interest (Imbens and Wooldridge, 2009). The Rubin model of potential outcomes consists of two pieces of information. The first piece of information refers to the treatment $D$. Let $D_{i}=1$ if individual $i$ is a member of the Swiss Latin language group, and $D_{i}=0$ if individual $i$ is a member of the Swiss German language group. ${ }^{14}$ We are interested in the effects of group membership on a set of outcomes $Y$ - attitudes towards the role of government, voting decisions, beliefs about the payoff to work, etc. Associated with each type of socialization is a potential voting decision $Y_{D}$, i.e. $Y_{1 i}$ is individual $i$ 's decision if $i$ is a member of the Latin speaking group, and $Y_{0 i}$ is individual $i$ 's decision if $i$ is a member of the Swiss German speaking group. For simplicity, we omit the subscript $i$ henceforth.

The individual causal effect of group membership on voting decisions can now be defined. It is simply the group membership difference in voting decisions $Y_{1}-Y_{0}$. The fundamental problem of causal inference is that this individual effect can not be observed. In the real world, individuals are either a member of the Latin speaking group or a member of the German speaking group but not both. This can be seen by characterizing observed voting decisions $Y=D Y_{1}+(1-D) Y_{0}$, i.e. we observe either $Y_{1}$ for the Latin native or $Y_{0}$ for the German native.

Can averages of the individual causal effect be identified? For instance, $E\left(Y_{1}-Y_{0} \mid D=\right.$ 1 ) is the average effect of being a member of the Swiss Latin speaking group for individuals speaking either French, Italian, or Romansh. This effect could be identified, for instance, if group membership were randomly assigned. Unfortunately, actual group membership is far from random. Further, the Swiss Latin speaking regions of Switzerland are located in areas

\footnotetext{
${ }^{13}$ Algan and Cahuc (2009) discuss this measure of civic virtue and its link with labor market institutions in detail.

${ }^{14}$ The treatment effects literature highlights that only those causes that could be experimentally manipulated can be regarded as proper treatments (Holland, 1986). Being a member of a particular language group is clearly a treatment that can be manipulated. For instance, children that are adopted by non biological parents are typically also moving across language borders (Björklund et al., 2006).
} 
with fairly mild climate,with an important services sector, high levels of immigration, etc. All these factors could by themselves also directly affect the need for social insurance and regulation.

The empirical strategy will entail contrasting residents of border municipalities on either side of the so called Roesti border. This strategy is intuitively appealing. Contrasting residents on either side of the language border preserves variation in group membership. But since spatial distance can be made arbitrarily small, any confound that varies with spatial distance will lose importance in the local contrast. For instance, policies which are set at the cantonal level and confound contrasts at the national level will not confound the local contrast. Also geographic factors such as weather, altitude, and access to highways and lake-view, that could affect firms' and individuals' location decisions, are likely to be balanced on either side of the language border (we test this formally below).

How do we implement the local border contrast? Implementation involves two steps. The first step defines each municipality's distance to the language border $F_{j}$. We use data on the driving distance in kilometers to proxy for economic distance between any pair of municipalities in Switzerland. ${ }^{15}$ We allocate municipalities to three groups. The first group are Latin border towns. These municipalities are majority Latin speaking and their nearest neighbor municipality is majority German speaking. Distance to the language border is set to zero for Latin border municipalities, i.e. $F_{j}=0$. The second group of municipalities is composed of mainland Latin speaking municipalities. We set distance to language border equal to the kilometer distance between any mainland Latin speaking municipality to the nearest Latin border town, i.e. $F_{j}>0$. The third group is composed of German majority municipalities with distance to the language border equal to the negative of kilometer distance of that municipality to the nearest Latin border municipality, i.e. $F_{j}<0$.

The second step involves contrasting mean voting outcomes on either side of the border. Under what conditions does this contrast inform us on the role of culture in shaping voting decisions? Let $E^{r}(X) \equiv \lim _{\epsilon \rightarrow 0} E\left(X \mid F_{j}=0+\epsilon\right)$ denote the limit of the mean of a variable $X$ when approaching the language border (at distance 0 ) from the right (r), i.e. when approaching the border from Swiss Latin territory. Equivalently, let $E^{l}(X) \equiv \lim _{\epsilon \rightarrow 0} E\left(X \mid F_{j}=0-\epsilon\right)$ denote the limit of the mean of $X$ when approaching the language border from the left (l), i.e. from Swiss German territory.

To make things more concrete, consider $E(D)^{l}$ and $E(D)^{r}$, i.e. the share native Latin speakers just to the left of the language border as opposed to the share Latin speakers in Latin border municipalities. Figure 3 allows guessing these quantities because it plots the share Latin speakers at distances to the language border not exceeding 100 kilometers (62 miles). The limit share Latin speakers in municipalities located on Swiss German territory is on the order of $E^{l}(D) \approx 0.15$. In contrast, the share Latin speakers in Swiss Latin border towns is on the order of $E^{r}(D) \approx .8$. This means that group membership changes sharply between municipalities

\footnotetext{
${ }^{15}$ Kilometer distance is certainly a better proxy for economic distance than Euclidian distance since Switzerland is quite a rugged country. Kilometer distance is also quite clearly dominated by a driving time distance measure. For instance, Lalive (2008) uses driving time to proxy for economic distance between pairs of municipalities in Austria. Nevertheless, kilometer distance is likely to be a good proxy for economic distance for pairs of municipalities that are located on the central, highly populated economic center of Switzerland (Mittelland). Kilometer distance may be more problematic proxy for economic distance for pairs of municipalities involving distances driven across the Alps, etc.
} 
located no further than a couple of kilometers apart. Since group membership changes sharply, we can therefore learn about the role of group membership for voting decisions by contrasting them at the language border. ${ }^{16}$ Note that our discussion exclusively focuses on the language border (dashed vertical line). This is because only that part of the graph informs on the causal role of group membership. The remaining segments of the graph provide interesting description of the spatial patterns in voting in Switzerland but have no causal interpretation.

Figure 3: Discontinuity in Native Language

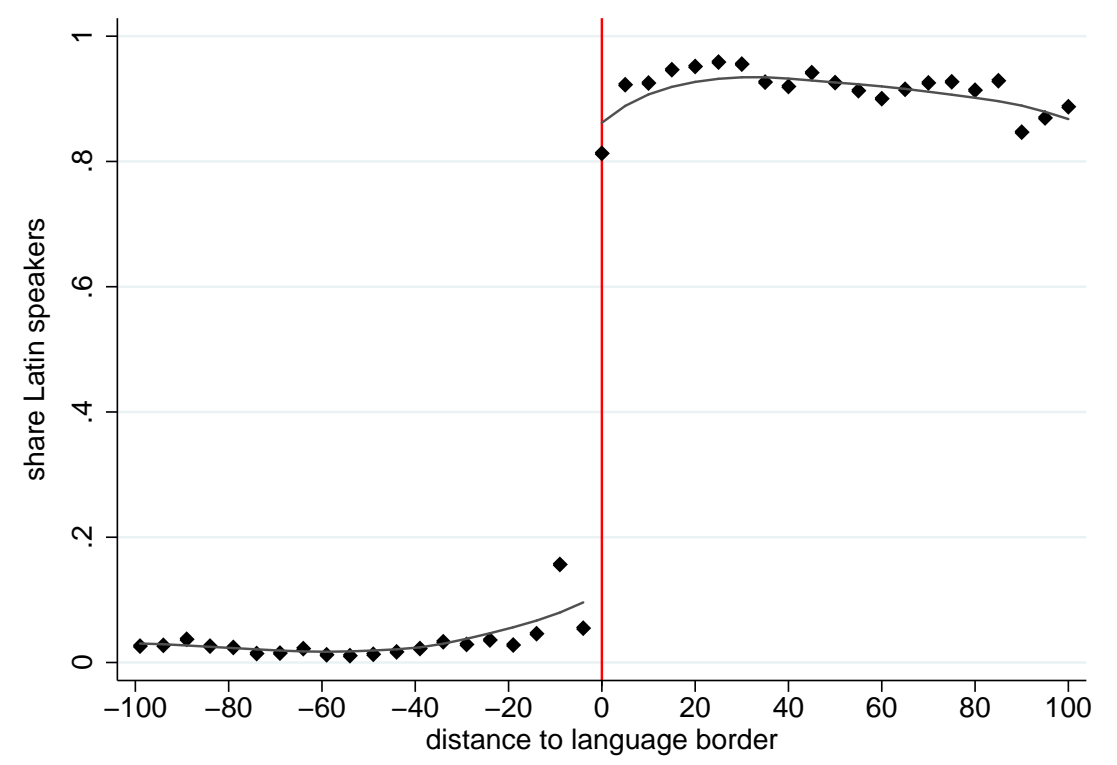

Notes: Dots show the share Latin (French, Italian or Romansh) speakers in the Swiss population at or above age 18 (eligible voters) speaking a Swiss official language (German, French, Italian or Romansh) for "bins" of communities. Communities are collected in bins by their distance to the language border, in $5 \mathrm{~km}$ intervals. Negative distances correspond to majority German-speaking communities, positive distances correspond to majority French-, Italian-, or Romansh-speaking communities. The vertical line indicates the language border, as detailed in the text. Also shown is a LOWESS fit to the bin-level shares, a locally weighted regression using $80 \%$ of the data to smooth each point.

Source: data from Federal Statistical Office, Neuchatel.

Contrasting the outcome $Y$ at the language border measures the average effect of language group membership on voting decisions provided that three key assumptions are satisfied. ${ }^{17}$

\footnotetext{
${ }^{16}$ In technical terms, the Swiss language border is a fuzzy spatial regression discontinuity design. Lee and Lemieux (2009) discuss problems with spatial regression discontinuity designs mainly related to endogenous mobility across the language border. While we can not exclude endogenous residential mobility, its quantitative magnitude is arguably too small to be strongly driving results.

${ }^{17}$ The effect is for residents of Latin border communities who are members of the Swiss Latin language group but who would be members of the Swiss German language group if they moved across the border multiplied by the share of language region compliers. This effect is a so-called local average treatment effect for the population at the language border. See Imbens and Angrist (1994) for a formal discussion of identification of local average treatment effects, and Hahn et al. (2001) for a formal proof of identification in a regression discontinuity setting. Lee and Lemieux (2009) discuss the key behavioral assumption as well as a range of settings with discontinuous assignment of treatments. It can be shown that the border contrast in the share speaking the Latin language equals $E^{r}(D)-E^{l}(D)=\operatorname{Prob}^{r}\left(D_{r}=1, D_{l}=0\right)$. This means that identification of the average effect of language group membership on voting decisions requires dividing the border discontinuity in voting by the border discontinuity in outcomes. Our preferred estimate of the border contrast in language is .7535 (see Table 7, row 1). This means
} 


$$
E^{r}(Y)-E^{l}(Y)=E^{r}\left(Y_{1}-Y_{0} \mid D_{r}=1, D_{l}=0\right) \operatorname{Prob}^{r}\left(D_{r}=1, D_{l}=0\right)
$$

The Appendix discusses the three assumptions along with evidence that is consistent with these three assumptions. The identification strategy is a fuzzy spatial regression discontinuity approach (RDD; see Hahn et al. (2001) for a general discussion of sharp and fuzzy RDD).

How can we estimate the average effect of language group membership on voting outcomes? It can be shown that the border contrast in the share speaking the Latin language equals $E^{r}(D)-E^{l}(D)=\operatorname{Prob}^{r}\left(D_{r}=1, D_{l}=0\right)$. This means that identification of the average effect of language group membership on voting decisions requires dividing the border discontinuity in voting by the border discontinuity in outcomes. Our preferred estimate of the border contrast in language is .7535 (see Table 7, row 1). This means that the border contrast in voting outcomes $E^{r}(Y)-E^{l}(Y)$ needs to be inflated by roughly 33 percent (i.e. multiplied by $1.327=1 / .7535$ ) to back out the average effect of language group membership on voting outcomes $E^{r}\left(Y_{1}-Y_{0} \mid D_{r}=\right.$ $\left.1, D_{l}=0\right)$.

\subsection{Estimation}

How can the border town contrast be estimated? It is not possible to just focus on the set of border municipalities. These municipalities would help estimating the mean voting pattern in Latin border towns $E^{r}(Y)$ because that is observed. What is not observed, however, is the counterfactual voting pattern in these municipalities. This counterfactual has to be estimated using data on Swiss German municipalities located "close" to the language border. We extrapolate using linear regression that focuses in all cases on municipalities located no further than 50 kilometers driving distance from the language border, i.e. we set the so-called half-width to 50 kilometers. ${ }^{18}$ For these municipalities, we estimate the following regression

$$
Y_{j}=\alpha_{l}+\delta L_{j}+\beta_{l 1} F_{j}+\beta_{l 2} F_{j}^{2}+\beta_{r 1} L_{j} \cdot F_{j}+\beta_{r 2} L_{j} \cdot F_{j}^{2}+X_{j}^{\prime} \gamma+\epsilon_{j}
$$

The key parameters in this regression are $\alpha_{l}$ and $\delta .{ }^{19}$ To see this, consider $E\left(Y_{j} \mid F_{j}=0, L_{j}=\right.$ $1)=\alpha_{l}+\delta$ and $E\left(Y_{j} \mid F_{j}=0, L_{j}=0\right)=\alpha_{l}$. This shows that $\delta$ estimates the border contrast in $Y$, i.e. $E^{r}(Y)-E^{l}(Y)$, and $\alpha_{l}$ measures the mean outcome in Latin border towns if they were German speaking. The parameters $\beta_{l 1}, \beta_{l 2}$ measure the spatial trend in voting and other outcome measures in Swiss German territory, while the parameters $\beta_{r 1}, \beta_{r 2}$ allow for a completely different spatial trend in Swiss Latin territory. The data vector $X_{j}$ contains background information on the municipalities, and - importantly - a full set of canton dummies. Canton dummies ensure that the parameter $\delta$ is identified by contrasting German and Latin border towns within the same canton. The parameter vector $\gamma$ captures the predictive power of background municipality characteristics. We will use equation (1) as our baseline regression specification to estimate the border contrast in $Y$. In all cases, we report standard errors that allow for clustering at the

that the border contrast in voting outcomes $E^{r}(Y)-E^{l}(Y)$ needs to be inflated by $1.327=1 / .7535$ to measure the average effect of language group membership on voting outcomes $E^{r}\left(Y_{1}-Y_{0} \mid D_{r}=1, D_{l}=0\right)$.

${ }^{18}$ We adopt an ad-hoc bandwidth because optimal bandwidth choice is complicated. We also report the sensitivity of our results to changes in the bandwidth, adopting, for instance a bandwidth of 25 kilometers. See Imbens and Kalyanaraman (2009) for a recent discussion of optimal bandwidth choice.

${ }^{19}$ See Lee and Lemieux (2009) for a comprehensive discussion of this regression specification. 
municipality level when working with individual data and heteroscedasticity robust standard errors when working with municipality data. ${ }^{20}$

\section{Culture and the Demand for Social Insurance}

This section discusses the causal effect of cultural background (as measured by the dominant language within a community) on the demand for social insurance (as measured by voting behavior on major reforms to the social insurance system) in Switzerland. In the first part of this section we give descriptive evidence on major referenda that took place in Switzerland over the last three decades. We then apply our spatial RDD methodolgy described in the last section to analyze the causal effect of cultural background on voting behavior.

\subsection{Voting on social insurance}

National votes and referenda are held on a regular basis on all kinds of issues in Switzerland. To ask for a referendum, voters collect signatures (50,000 within three months for a referendum on a government policy, 100,000 for a voter initiative on a new amendment to the constitution) and the parliament checks if the initiative is consistent with existing laws. ${ }^{21}$ A national vote is held on the issue if the parliament agrees on holding it. For most referenda and initiatives a simple majority rule is applied. International treaties need to be approved by the majority of the people and the cantons.

These national votes provide a wealth of data on the opinions of Swiss voters with respect to many different subjects. The voting data is publicly available since 1980 . Voting data contain information on the number of eligible voters, number of votes cast, number of valid votes, and number of votes in favor ("Yes") or not ("No"). The data cover each of the roughly 2,700 Swiss municipalities.

Table 2 provides a list of all votes studied in this paper along with their voter turnout and results in the two language regions. All these votes are national referenda and intend to change national law. All voters in Switzerland decide on the same issue.

We start with health insurance because health risks are, arguably, the most broadly relevant risk to a person's human capital. Panel A of table 2 contains the results of three votes on health insurance. The 1994 vote on the introduction of mandatory health insurance constituted a major change in the health insurance system. It introduced mandatory basic health insurance for all residents, subsidies for the poor and it abolished the possibility to demand different premia based on age, preexisting conditions, and gender. The referendum was accepted with a narrow 50.9 percent yes-votes. While Swiss-Germans rejected the referendum with 46 percent yes-votes, Latin voters strongly supported this referendum. The gap between the two language regions was almost 20 percentage points. In 2007, a referendum on the introduction of a single public health insurance company was rejected by the majority of the population. This referendum proposed a single insurance company for basic health insurance (which is quite comprehensive

\footnotetext{
${ }^{20}$ We have also explored clustering standard errors with respect to distance to the language border - our socalled forcing variable. This type of clustering has been suggested by Card and Lee (2008). Our conclusions are not affected by a change in the level of clustering.

${ }^{21}$ Note: there is no check if the initiative is consistent with international law, c.f. Minaret initiative in 2009
} 


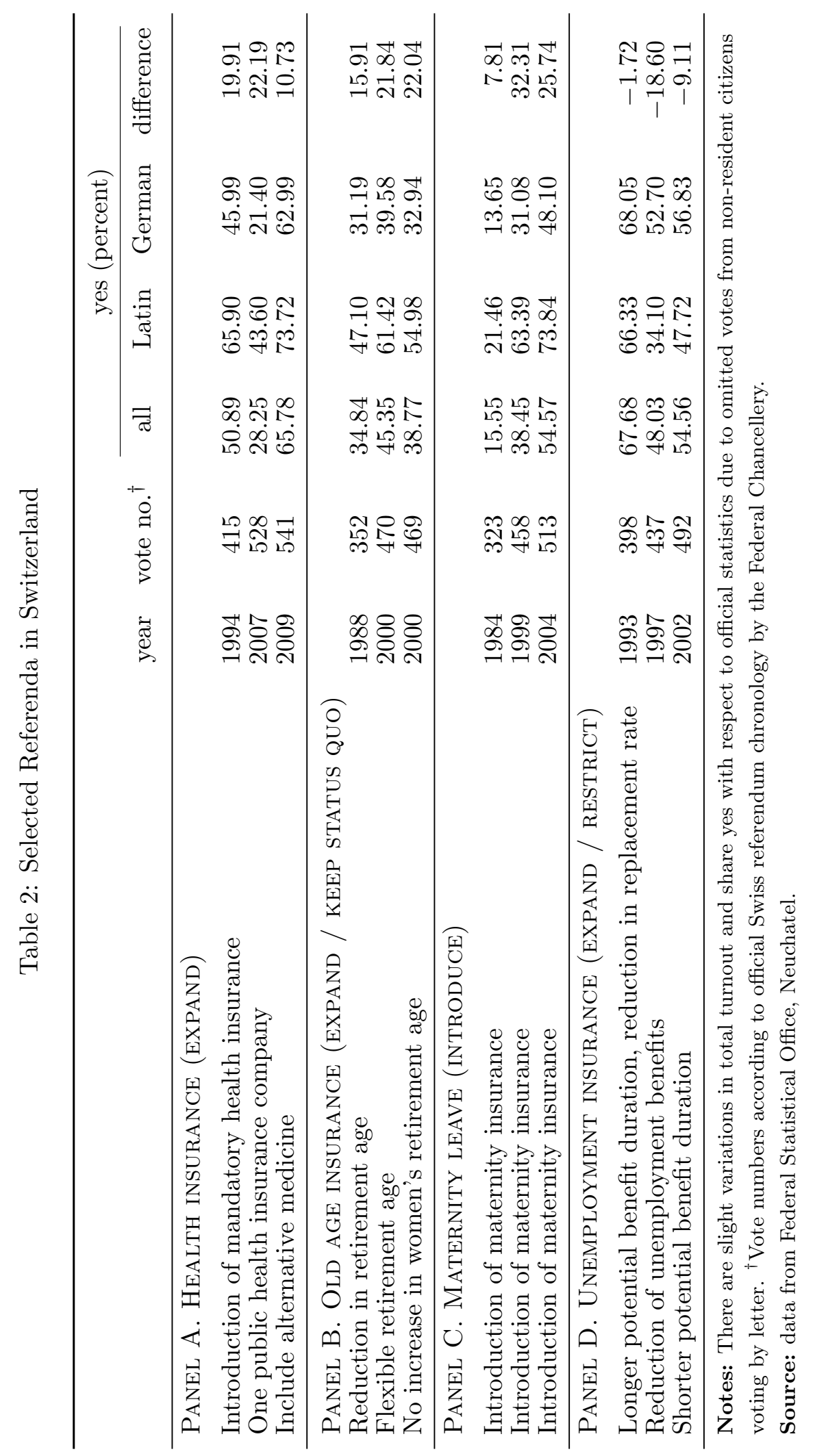


in Switzerland) and premia based on income and wealth of the insured (instead of equal premia for everyone). In this vote, the German-Latin gap was even stronger with 22 percentage points more support for the vote by Swiss Latins. The 2009 vote had as its purpose to include alternative medicine into the list of treatments that have to be paid by mandatory health insurance. This expansion of health insurance was accepted by a majority of voters, with much higher support in the Latin region.

Several important referenda were held also with respect to the second important field of social insurance, the old-age social security system. Panel B of table 2 shows three referenda on old age insurance that were rejected by a majority of Swiss voters. In all three votes the issue was whether to decrease the statutory retirement age of the pay-as-you-go pillar of the Swiss old age insurance (AHV). This first pillar is in place since 1947 and provides the main source of income after retirement for low-wage workers. Lowering the eligibility age without a corresponding (marginally) actuarially fair discount of benefits clearly implies a redistribution of income from high wage to low wage workers and from young to old age individuals. Even though all three referenda were turned down at the poll, the Latin-speaking population of Switzerland would have accepted both referenda in 2000. In all three votes, the Latin-German-gap was as large as 15 and 22 percentage points.

Panel C. in table 2 depicts voting results on three federal referenda on the introduction of maternity insurance. Both in 1984 and 1999 introduction was dismissed and Switzerland introduced maternity insurance not until 2005. The Latin-German-gap is striking in all three votes but particularly so in 1999 and $2004 .^{22}$

Unemployment insurance is a national program that was reformed several times since 1980. Panel D. shows two votes introducing more restrictive rule and one vote that changed rules on both directions. The main component of the 1993 vote was a reduction in unemployment benefits. Voters were less aware of the fact that this reform also proposed to extend unemployment benefit duration. In this vote, eventually accepted by the majority, no significant Latin-German-gap shows up. However, there were large differences in the other two votes, both of which made the unemployment insurance system less generous. The vote about a reduction of unemployment benefits in 1997 was turned down; and the vote on shorter benefit durations in 2002 was accepted. In both votes, the Latin-German-gap was large, 9 percent in the 1997 vote and 19 percent in the 2002 vote.

\subsection{The Latin-German gap in demand for social insurance}

We start by plotting the relevant outcome variable (percentage yes-votes) with respect to distance to the language border. Doing so provides a graphical indicator for the presence of a discontinuous jump in the outcome variable at the language border, i.e. distance zero. To estimate the border contrast in voting outcomes, we implement equation 1 and report the estimate of the parameter $\delta$. This parameter is identified by a change in majority language within cantons, holding distance to language border, canton of residence and a wealth of municipality background characteristics constant. This parameter therefore measures the causal effect of language group membership on voting decisions at the language border.

\footnotetext{
${ }^{22}$ Language regions also differ in terms of the role of women. See Steinhauer (2010) for further details.
} 
Figure 4 provides distance-to-border graphs for 15 national referenda on social insurance. We grouped the votes according to the type of insurance. Panel A in Figure 4 shows three referenda related to health insurance. The 1994 vote introduced universal mandatory basic health insurance for all residents, subsidies for the poor and ended the possibility to demand different premia based on age, preexisting conditions, and gender. There is a strikingly clear discontinuity in support for the proposal (sub-graph 4A.a.). Whereas this proposition tended to please barely more than half of the residents of German language border towns, 7 out of 10 Latin border voters tended to voice support for universal social health insurance. In 2007, voters decided on a proposal to nationalize the health insurance industry. This proposal gathered support from roughly 3 in 10 voters in German border towns. In contrast, more than 4 out of 10 voters in Latin border towns tended to favor this proposal (sub-graph 4A.b.). In 2009, the catalogue of covered treatments was to be extended to include alternative medicine. This proposal was met with approval among 2 out of 3 German border town voters. In contrast, almost 3 out of 4 Latin border town residents were in favor of extending the catalogue of covered treatments. Overall, there is a striking discontinuity in the demand for social health insurance at the Swiss language border.

Panel B in Figure 4 shows three referenda on social security - or old age insurance. All three votes the issue intended to expand social security by lowering (or keeping constant) the age of early retirement. In all three cases, there is a clear difference in terms of the proportion of voters favoring a reduction (or maintaining) the statutory age of retirement. While roughly 3 to 4 out of 10 voters in German speaking border towns support reductions in the early retirement, the corresponding share attains a level of 5 out of 10 voters supporting lower retirement ages (sub-graphs 4B.a.-B.c.).

Panel C in Figure 4 depicts voting results on three federal referenda on the introduction of maternity insurance. Both in 1984 and 1999 introduction was dismissed and Switzerland introduced maternity insurance not until 2004. The pattern is quite striking, with large discontinuities at the border in 1999 and 2004 (sub-graphs 4C.b. and 4C.c.). ${ }^{23}$

Panel D in Figure 4 shows three votes on unemployment insurance. The 1993 referendum entailed both a reduction of the benefit replacement rate from $80 \%$ to $70 \%$ for job seekers with no dependents, who earned high pre-unemployment incomes, along with an extension of the potential benefit duration. There is no visible discontinuity in the 1984 voting results on prolonging potential benefit duration (sub-graph 4E.a.). This is probably due to the fact that the issue at hand neither clearly extended nor clearly tightened unemployment insurance. In contrast, both the 1997 and 2002 votes discussed issues related to tightening UI. The 1997 vote reduced the benefit replacement rate, while the 2002 vote shortened benefit duration. There are strong discontinuities in support for these two votes. While more than 5 out of 10 German border voters supported reductions in coverage, fewer than 5 out of 10 Swiss Latin border voters were in favor of tightening UI (sub-graphs 4E.b. and 4E.c.).

So far, we have looked at only a graphical description of voting at the language border. Do

\footnotetext{
${ }^{23}$ Note that Latin and German residents also differ with respect to their view regarding the role of women. For instance, 23.7 percent of German region residents agree with the ISSP 2002 survey item "A man's job is to earn money; a woman's job is to look after the home and family." The corresponding share in Latin regions is 19.4 percent. See Steinhauer (2010) for further discussion of this issue.
} 
Figure 4: Voting on Social Insurance

A. Health Insurance

a. Introduce (1994)

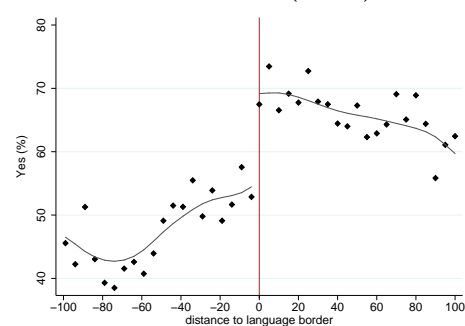

a. Reduce Ret. Age (1988)

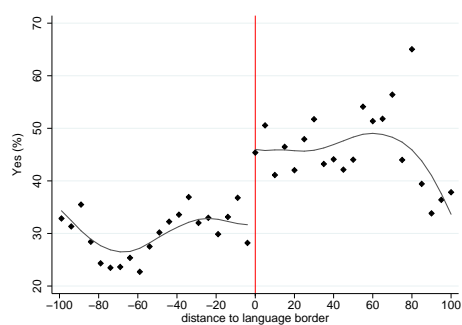

a. Introduce (1984)
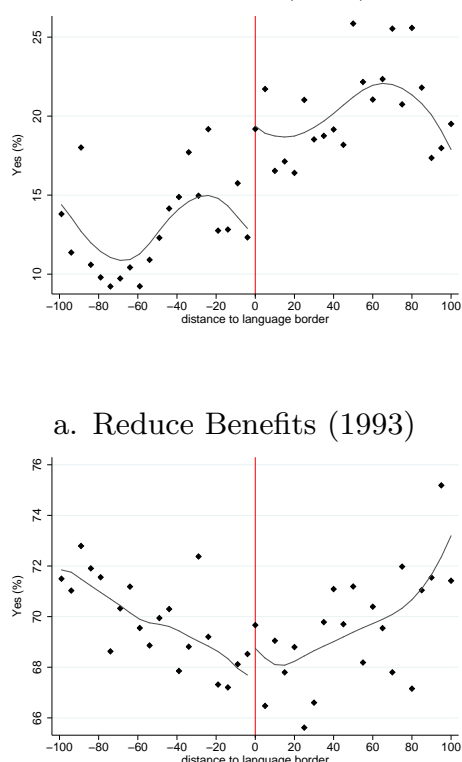

b. Public Health Insurer (2007)

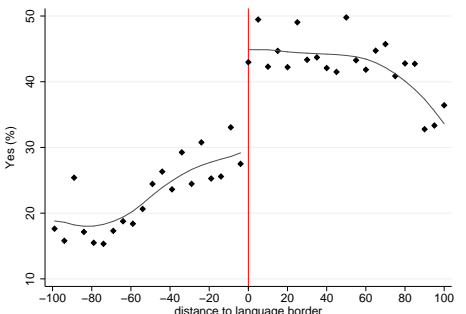

c. Alternative Medicine (2009)

B. Social Security

b. Flexible Ret. Age (2000)

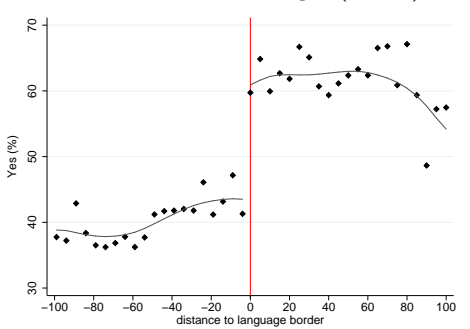

c. Keep Women's Ret. Age

(2000)

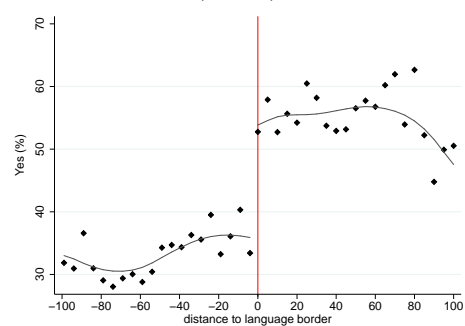

\section{Maternity Leave}

b. Introduce (1999)

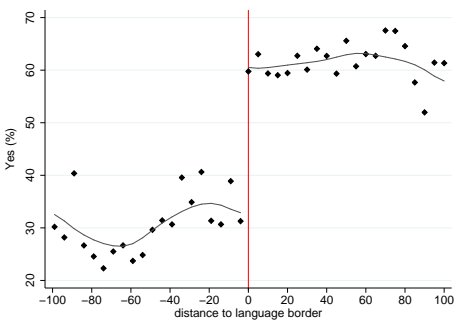

c. Introduce (2007)

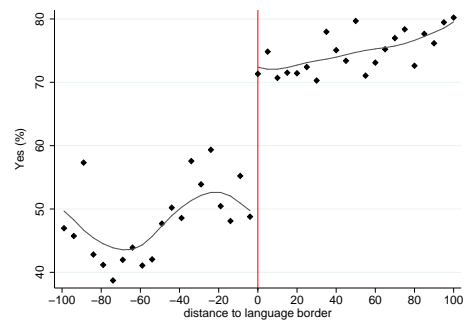

D. Unemployment Insurance

b. Reduce Benefits (1997)

c. Shorten Duration (2002)
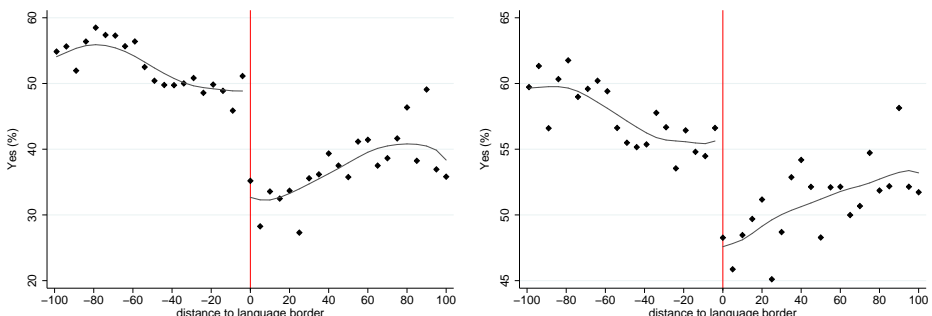

Notes: See notes to figure 3. Dots show the percent Yes-votes of all valid cast votes, per 5km-bin of communities. Year the vote was held and number of the vote according to the official directory in parentheses. Negative=German-speaking part; positive=French-/Italian-/Romansh-speaking part. 
these results withstand the addition of canton dummies and control variables? Table 3 discusses the causal effects of language group membership on voting outcomes. The table reports a series of 4 different estimation results. Column (1) discusses the border contrast adopting a $50 \mathrm{~km}$ window around the language border, with a quadratic two sided trend (equation 1 without the $X$ vector). Column (2) adds canton dummies - shifting to within canton identification - and municipality background controls (see Tables 7 Panels A and B and 8 Panel C for the full list of controls). Columns (3) and (4) keep the $X$ vector and assess sensitivity to functional form using the two approaches recommended by Lee and Lemieux (2009). Column (3) adopts a local linear approach, i.e. reduces the bandwidth to $25 \mathrm{~km}$ and shifts to a linear spatial trend on both sides of the language border. Column (4) adopts a polynomial approximation approach introducing third order terms in distance to border.

Panel A in Table 3 provides results on the role of language group membership for the demand for social health insurance. Row 1 discusses introduction of universal basic coverage in 1994 . Results in column (1) suggest that the Latin German gap in support for universal coverage is about 7.4 percentage points. Column (2) reports results that include canton dummies (shifting to within canton identification) and a full set of control variables. Doing so appears to be important as the estimated Latin German gap shrinks to just barely below 5 percentage points. Columns (3) and (4) provide sensitivity analysis for column (2). Column (3) discards all municipalities further than $25 \mathrm{~km}$ away from the language border and adopts a linear spatial trend. The resulting Latin German gap in support for universal health insurance increases somewhat to 6 percentage points. Column (4) assesses sensitivity to misspecified spatial trends by adding two third order terms in distance to language border (one for each language region) to model (1) while keeping the original 1177 municipalities located at $50 \mathrm{~km}$ distance from the language border. Results indicate that Latin border municipalities are 4.5 percentage points more in favor of universal health care than would be expected from their German counterparts. Thus, the baseline result of a Latin German gap of 4.8 percentage points (column 2) for the 1994 vote do not appear to be sensitive to misspecified functional form.

Row 2 in Panel A discusses the proposal to nationalize health insurance. The health insurance market is currently characterized by a large number of private health insurers that are regulated by the government. The 2007 proposal, elaborated by Pascal Broulis - a politician from the Latin speaking part of the country - suggested to nationalize the entire industry. Results in column 2 suggest that Latin border municipalities were 11.9 percentage points more likely to support this proposal than their German counterparts. This results is, again, not sensitive to misspecified functional form (columns 3 and 4). Row 3 in Panel A discusses extending the basic health catalogue to alternative medicine (homeopathy, etc.). Latin border municipalities were 5.1 percentage points more likely to vote for this extension of social insurance than their German counterparts. Results hold up in column 3 but get insignificant in column 4. Overall, results in Panel A of Table 3 consistently identify stronger support for universal health insurance in Latin border towns despite facing identical actual levels of social insurance (section 2).

Panel B in Table 3 discusses changes to the old age pension system. The first vote in 1988 proposes to reduce the statutory retirement age, i.e. an expansion of coverage. Results in column 2 indicate that support for this proposal is 6.2 percentage points higher in Latin border towns compared to their German counterparts. This result is robust to mis-specification of spatial 
trends (columns 3 and 4). The second and third vote proposed both to give workers more freedom to choose when to retire and to keep women's retirement age at 62 years (instead of gradually increasing it to match men's retirement age of 65 years). Both proposals are consistently more strongly supported in Latin border towns compared to their German counterparts. The Latin excess support is on the order of 10.3 percent for the proposal to have a flexible system and 9.5 percentage points for the proposal to keep women's retirement age constant according to our baseline specification (column 2). Both results hold up to sensitivity analyzes in columns 3 and 4.

Panel C in Table 3 discusses three proposals to introduce maternity leave. The first proposal, while rejected in 1984, was met with 3.3 percentage points more enthusiasm in the Latin border community than would be expected from their German counterparts. The second proposal, while voted rejected in 1999, was met with 9.8 percentage points more enthusiasm in the Latin border community than would be expected from their German counterparts. The final proposal who led to the decision to introduce universal paid maternity leave of 12 weeks was, was, yet again, favored by 9.9 percentage points more voters in the Latin border towns than expected from the German border community. With the exception of one vote (1984), results hold up to the sensitivity analyzes in columns 3 and 4 .

Panel D in Table 3 discusses three proposals to reform unemployment insurance (UI). The first proposal in 1993 entailed a reduction of the benefit level, but it also extended unemployment benefit duration. This proposal was opposed by 3.4 percentage points more voters in Latin border communities compared to their neighbors in majority German speaking territory. Voters again decided on a surprise reduction of benefits introduced by the Government in early $1997 .^{24}$ Unions organized a national referendum on this decision and managed to overturn this surprise benefit reduction. Interestingly, support for the reduction in benefits was 3.4 percentage points stronger in German border towns compared to the Latin border society. The third proposal, voted in 2002, suggested to reduce benefit duration for any job seeker aged 55 years or less. This clear reduction of UI coverage was opposed by 2.3 percentage points more voters in Latin border towns compared to their neighbors at the fringes of mainland German speaking territory. Results hold up to the sensitivity analyzes reported in columns 3 and 4 .

In sum, we find strong evidence for higher demand for social insurance and redistribution by individuals of Latin-speaking communities compared to their neighbors just across the language border. Thus, results are consistent with a significant role of culture in determining the demand for social insurance of risks to health and work.

\section{Possible explanations}

This section discusses three competing explanations of the Latin-German gap in support for social insurance: informal insurance, beliefs, and the media. Understanding the relevance of these explanations is key to formulate policy responses.

\footnotetext{
${ }^{24}$ Stutzer and Lalive (2004) discuss the political context of this referendum and use this referendum to proxy for the norm to live off one's own income.
} 
Table 3: Voting on Social Insurance

Dependent variable

Percent Yes

Bandwidth

Distance

Control variables

Number of observations

\begin{tabular}{cccc}
\hline $50 \mathrm{~km}$ & $50 \mathrm{~km}$ & $25 \mathrm{~km}$ & $50 \mathrm{~km}$ \\
quadratic & quadratic & linear & cubic \\
no & yes & yes & yes \\
1,177 & 1,177 & 562 & 1,177
\end{tabular}

year

$(2)$

(3)

(4)

\begin{tabular}{|c|c|c|c|c|c|}
\hline \multicolumn{6}{|c|}{ Panel A. Health insurance } \\
\hline $\begin{array}{l}\text { Introduction of man- } \\
\text { datory health insurance }\end{array}$ & 1994 & $\begin{array}{l}7.42 \\
(1.23)^{* * *}\end{array}$ & $\begin{array}{l}4.84 \\
(1.09)^{* * *}\end{array}$ & $\begin{array}{l}6.07 \\
(1.06)^{* * *}\end{array}$ & $\begin{array}{l}4.51 \\
(1.57)^{* * *}\end{array}$ \\
\hline $\begin{array}{l}\text { One public health } \\
\text { insurance company }\end{array}$ & 2007 & $\begin{array}{l}13.36 \\
(1.04)^{* * *}\end{array}$ & $\begin{array}{l}11.92 \\
(0.97)^{* * *}\end{array}$ & $\begin{array}{l}12.42 \\
(0.97)^{* * *}\end{array}$ & $\begin{array}{l}10.38 \\
(1.26)^{* * *}\end{array}$ \\
\hline $\begin{array}{l}\text { Include alternative } \\
\text { medicine }\end{array}$ & 2009 & $\begin{array}{l}6.83 \\
(1.69)^{* * *}\end{array}$ & $\begin{array}{l}5.06 \\
(1.42)^{* * *}\end{array}$ & $\begin{array}{l}5.19 \\
(1.36)^{* * *}\end{array}$ & $\begin{array}{c}3.07 \\
(2.23)\end{array}$ \\
\hline \multicolumn{6}{|c|}{ PANEL B. Social SECURITy (EXPAND / KeEP STATUS QUO) } \\
\hline $\begin{array}{l}\text { Reduction in } \\
\text { retirement age }\end{array}$ & 1988 & $\begin{array}{l}9.56 \\
(1.35)^{* * *}\end{array}$ & $\begin{array}{l}6.17 \\
(1.03)^{* * *}\end{array}$ & $\begin{array}{l}7.72 \\
(1.07)^{* * *}\end{array}$ & $\begin{array}{l}4.62 \\
(1.50)^{* * *}\end{array}$ \\
\hline Flexible retirement age & 2000 & $\begin{array}{l}12.95 \\
(1.36)^{* * *}\end{array}$ & $\begin{array}{l}10.26 \\
(1.11)^{* * *}\end{array}$ & $\begin{array}{l}11.09 \\
(1.10)^{* * *}\end{array}$ & $\begin{array}{l}8.58 \\
(1.61)^{* * *}\end{array}$ \\
\hline $\begin{array}{l}\text { No increase in women's } \\
\text { retirement age }\end{array}$ & 2000 & $\begin{array}{l}12.46 \\
(1.14)^{* * *}\end{array}$ & $\begin{array}{l}9.53 \\
(0.87)^{* * *}\end{array}$ & $\begin{array}{l}10.29 \\
(0.88)^{* * *}\end{array}$ & $\begin{array}{l}8.42 \\
(1.27)^{* * *}\end{array}$ \\
\hline \multicolumn{6}{|c|}{ Panel C. Maternity leave (introduce) } \\
\hline $\begin{array}{l}\text { Introduction of } \\
\text { maternity insurance }\end{array}$ & 1984 & $\begin{array}{l}5.01 \\
(0.84)^{* * *}\end{array}$ & $\begin{array}{l}3.30 \\
(0.79)^{* * *}\end{array}$ & $\begin{array}{l}3.47 \\
(0.80)^{* * *}\end{array}$ & $\begin{array}{c}1.93 \\
(1.31)\end{array}$ \\
\hline $\begin{array}{l}\text { Introduction of } \\
\text { maternity insurance }\end{array}$ & 1999 & $\begin{array}{l}11.87 \\
(1.55)^{* * *}\end{array}$ & $\begin{array}{l}9.79 \\
(1.45)^{* * *}\end{array}$ & $\begin{array}{l}10.32 \\
(1.32)^{* * *}\end{array}$ & $\begin{array}{l}6.93 \\
(2.35)^{* * *}\end{array}$ \\
\hline $\begin{array}{l}\text { Introduction of } \\
\text { maternity insurance }\end{array}$ & 2004 & $\begin{array}{l}12.34 \\
(1.62)^{* * *}\end{array}$ & $\begin{array}{l}9.85 \\
(1.36)^{* * *}\end{array}$ & $\begin{array}{l}10.76 \\
(1.33)^{* * *}\end{array}$ & $\begin{array}{l}8.07 \\
(2.13)^{* * *}\end{array}$ \\
\hline \multicolumn{6}{|c|}{ PANEL D. UnEMPloyment insurance (TIGHTEN) } \\
\hline Reduce benefits & 1993 & $\begin{array}{l}-3.34 \\
(1.83)^{*}\end{array}$ & $\begin{array}{l}-3.67 \\
(1.60)^{* *}\end{array}$ & $\begin{array}{l}-2.82 \\
(1.48)^{*}\end{array}$ & $\begin{array}{l}-5.32 \\
(2.52)^{* *}\end{array}$ \\
\hline Reduce benefits & 1997 & $\begin{array}{l}-5.30 \\
(1.36)^{* * *}\end{array}$ & $\begin{array}{l}-3.41 \\
(1.05)^{* * *}\end{array}$ & $\begin{array}{l}-3.92 \\
(1.04)^{* * *}\end{array}$ & $\begin{array}{l}-5.87 \\
(1.57)^{* * *}\end{array}$ \\
\hline $\begin{array}{l}\text { Shorten benefit } \\
\text { duration }\end{array}$ & 2002 & $\begin{array}{l}-4.33 \\
(1.51)^{* * *}\end{array}$ & $\begin{array}{l}-2.28 \\
(1.02)^{* *}\end{array}$ & $\begin{array}{l}-2.69 \\
(1.05)^{* *}\end{array}$ & $\begin{array}{l}-4.03 \\
(1.52)^{* * *}\end{array}$ \\
\hline
\end{tabular}

Notes: Table entries are estimates of the Latin dummy coefficient (equal to 1 if majority of community population speaks a Latin language, 0 otherwise). Robust (HC3) standard errors in parentheses. ${ }^{*} p<0.10,{ }^{* *} p<0.05,{ }^{* * *} p<0.01$. All regressions include distance, distance squared and interaction terms with the Latin dummy. Column (2) is based on equation 1. Control variables on community level are canton dummies, age, gender, and education structure, population size of community, share protestant, catholic, foreigners, unemployment rate, sectoral structure, geography: agglomeration, touristic, altitude, land use (arboriculture, culture, alps, forest, unproductive, constructed), proximity to lakes.

Source: data from Federal Statistical Office, Neuchatel. 


\subsection{Informal Insurance}

The demand for social insurance and work regulations depends importantly on the availability of informal insurance, which can be a substitute for publicly provided insurance and redistribution (Bloch et al., 2008). Informal insurance can either be the family or close friends where insurance is more strongly based on bilateral links between network members; or insurance groups, where the group collectively insures the network member. The degree of insurance depends crucially on norms regarding mutual help. In the present context, it could be that norms with respect to mutual help might be lower in the Latin region of Switzerland leading to less stable social networks and less informal insurance. As a result a higher demand for social insurance could emerge. ${ }^{25}$

A related argument holds that social capital creates informal insurance. There is no single definition of social capital. However, Durlauf and Fafchamps (2005b) argue that there are three underlying main ideas of social capital: (i) it is beneficial for members of a group; (ii) these benefits arise through shared norms and values, which influence expectations and behavior; and (iii) these norms and values evolve through informal organizations, such as associations. ${ }^{26}$

We explore the relevance of informal insurance and social capital exploiting data from the Swiss Household Panel (SHP). ${ }^{27}$ Panels a and b of figure 5 look at the number of an individual's relatives and friends (strong ties), and the number of an individual's neighbors and colleagues (weak ties). ${ }^{28}$ Since the SHP offers detailed information on individuals' location of residence,

\footnotetext{
${ }^{25}$ Angelucci et al. (2009) present evidence from a quasi-experimental study on transfers within extended family networks. Studying cash transfers from the state in Mexico, they show that ineligible individuals that are member of an extended family network do profit more from cash transfers within a village than ineligible individuals that do not have such a family network. There is a larger literature on risk pooling within ethnic groups and within families in developing countries. Udry (1994) develops a model of risk sharing within ethnic groups and tests it with data from Tanzania. He finds substantive but imperfect risk pooling between families. Fafchamps and Lund (2003) stress the importance of family ties and networks of friends in smoothing income shocks in rural Philippines. They show that risk pooling is not done on village level but rather within personal networks.

${ }^{26}$ Carter and Castillo (2004) provide evidence on the effect of different social capital in communities in Honduras in recovering from a hurricane catastrophe. Communities with stronger social norms rebuilt their houses quicker than communities with lower norms. However, only members of the respective networks profited. Narayan and Pritchett (1999) proxy in their study about Tanzania social capital as an index containing the number of club memberships and some characteristics of the respective clubs. They argue that, among others, greater associational activity is linked to greater sharing of household risk and informal insurance. Putnam (2001) claims that being member of an association or a club that meet regularly is (besides contact with family, friends, neighbors,...) a sign of developed social capital. He especially states that a decrease in social capital in the US over the last years has led to a significant decrease in club memberships.
}

${ }^{27}$ The SHP is a yearly conducted panel survey in Switzerland that aims to asses a broad range of questions linked to living in Switzerland. Among others, it asks about labor market participation, financial situation, social networks, social participation, and values in different fields. The SHP started in 1999 with a random sample of 5'074 households. In 2004, 2'538 households were added to the original sample because of attrition problems. The sample was constructed containing only Swiss citizens since birth, because specific Swiss cultural traits that are transmitted by family and social networks should be strongest for individuals with a Swiss family. Furthermore, only individuals that have a Swiss mother tongue were kept in the sample, because language is important for integration to social networks. Finally, only individuals aged 18 or older are investigated, so that our sample can be compared to the voting age population. This yields a final sample of 8'107 individuals in 5'211 households. Note however, that not all individuals answer to all questions.

${ }^{28}$ This vocabulary leans on the work of Granovetter (1973) on strong and weak ties. He argues that as well 
we can apply the spatial regression discontinuity approach. Panels a and b reveal that neither the number of strong social ties nor the number of weak social ties show large differences at the language border. Latin Swiss individuals have somewhat stronger family ties but German Swiss individuals are better connected to neighbors and colleagues (more "weak social ties"). The evidence on social networks is mixed.

The SHP also contains information on club membership in eight different kinds of associations. Panel c of figure 5 presents evidence on active club memberships in these different associations. Respondents who live in Latin border municipalities appear to be members of fewer clubs than their neighbors living in German border municipalities. ${ }^{29}$ This evidence suggests that a higher demand for social insurance in the Latin side could partly result from lower social capital.

Figure 5: Social Networks and Social Capital

a. Strong ties (relatives and friends)

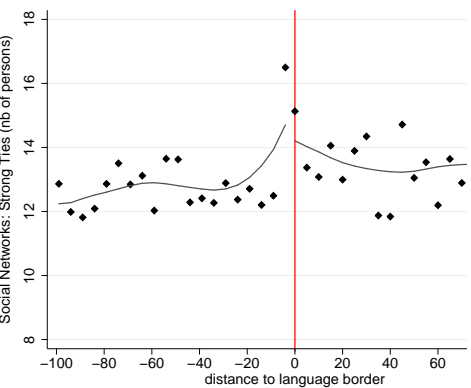

b. Weak ties (neighbors and colleagues) c. Club membership (active member)
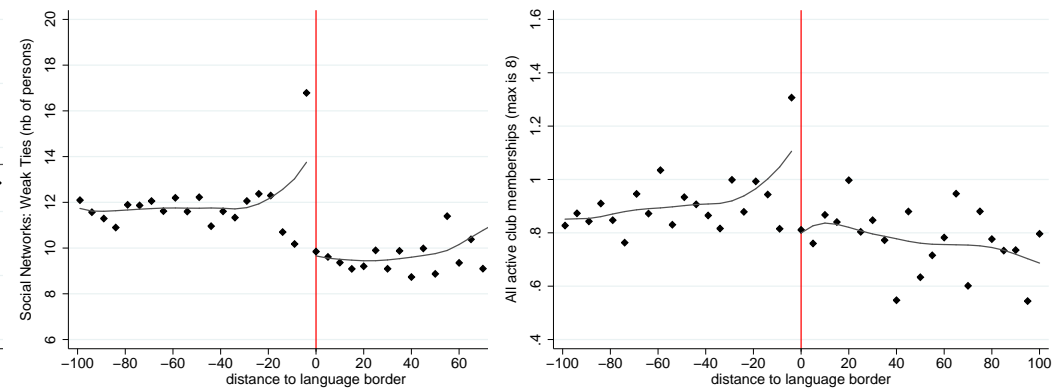

Notes: negative=German-speaking part; positive=French-/Italian-/Romansh-speaking part. Strong ties: Sum of number of relatives and number of friends (32'004 valid observations). Weak ties: Sum of number of neighbors and colleagues (31'360 valid observations). Club membership: Count number of clubs that a person is an active member in. Maximum number of clubs is eight. (32'259 valid observations).

Source: Swiss Household Panel (1999-2008).

Table 4 provides a detailed econometric analysis of the possible role of social networks and social capital. Column 1 of Panel A shows that respondents have, on average, 7.4 relatives and 5.7 close friends. Columns (1) to (4) reports the estimated discontinuity at the language border. Regressions control for age, education, gender, and an extensive set of municipality characteristics. ${ }^{30}$ Using these controls, we find that strong social ties are significantly higher for Latin speakers. For weak ties, we do not find statistically significative differences among language groups.

A fact that could confound the analysis in columns (1) to (2) is that unemployment is higher in Latin regions than in Swiss-German regions. Unemployed individuals might have more need

\footnotetext{
strong as well as weak ties are important in a sociology to spread information.

${ }^{29}$ One reason among a multitude of others could be that the Latin Swiss appear to follow Groucho Marx's suggestion to "never be a member of a club that accepts me as one of its members" more than the German Swiss.

${ }^{30}$ Permanent population, percentage of protestants and of catholics, percentage foreigners, municipal unemployment rate, economic sectoral composition, agglomeration, touristy area, altitude of the municipality, lake border, surface, and land use.
} 
for (informal) insurance and also more available time to spend to see friends. Column (5) conducts the same analysis as column (2), using only observations of employed individuals. Differences in social networks vanish if looking at employed individuals only.

Panel B of table 4 shows evidence on social capital, approximated by active membership in an association or a club. "All clubs" is a count variable that can take values between zero and eight, depending on the number of different clubs in which the individual is active. We subdivided the eight club-categories into clubs with a redistributive goal (parents organization, syndicate, charitable organization, women organization, tenants rights), and into club without such a goal (sport or leisure, culture, protection of the environment). Results show that Latin individuals are significantly less frequently members of a club. This is true for the whole sample as well as the sub-sample of employed individuals. The difference is quantitatively important. The estimated gap at the language border is as large as one fourth of the mean of club memberships directly at the language border.

We conclude that Latin Swiss hold somewhat stronger social ties, especially with close friends, controlling for socio-economic (age, sex, eduction) and municipality characteristics, as well as year and canton fixed effects. However, Latin Swiss individuals also hold less social capital as measured by participation in clubs and associations. Taken together, informal insurance through social networks and through social capital does not seem to be a major explanatory factor for the observed differences in voting behavior.

\subsection{Ideology}

Bénabou and Tirole (2006) argue that strong "Beliefs in a Just World", that is believing that one gets what one deserves, leads societies to adopt welfare systems with little redistribution and social insurance and that welfare systems with little indirect redistribution can foster these beliefs in a just world. ${ }^{31}$ This interplay of beliefs and real-life experience may generate multiple equilibria, such as an "American equilibrium" with strong beliefs in the "American dream" and low redistribution, and a "European equilibrium" with weak beliefs in a just world and a large welfare state.

In Figure 1 we have seen that the German-Swiss are quite close to Anglo-Saxon countries when asked whether they are in favor of income redistribution through the government. Using data from the World Value Survey 1996, we can dig deeper. In this wave, individuals were ask (on scale between 1 and 10) whether they think they have "freedom of choice (10) or no control at all over the way life turns out (1)". This survey item is designed to measure an individual's locus of control (LOC). ${ }^{32}$ Figure 6a shows that most German Swiss think they have high freedom and high control over their lives. While also a majority among Latin Swiss thinks this way, a non-negligible fraction Latin-Swiss answers that freedom and control over life is much weaker. Similarly, the World Value Survey 1996 asks individuals whether they think that "hard work brings a better life (1) or success is a matter of luck and connection (10)". Figure 6b shows that

\footnotetext{
${ }^{31}$ Earlier important contributions focusing on the divergent belief concerning upward income mobility include Piketty (1995) and Bénabou and Ok (2001).

${ }^{32}$ Verme (2009) studies the relationship between happiness and locus of control using world values survey data.
} 
Table 4: Language Border Contrasts in Informal Insurance

\begin{tabular}{|c|c|c|c|c|c|c|}
\hline & Mean & (1) & (2) & $(3)$ & $(4)$ & $(5)$ \\
\hline Sample & All & All & All & All & All & Employed \\
\hline Bandwidth & $50 \mathrm{~km}$ & $50 \mathrm{~km}$ & $50 \mathrm{~km}$ & $25 \mathrm{~km}$ & $50 \mathrm{~km}$ & $50 \mathrm{~km}$ \\
\hline Distance & no & quadratic & quadratic & linear & cubic & quadratic \\
\hline Control variables & no & no & yes & yes & yes & yes \\
\hline \multicolumn{7}{|l|}{ A. Social Networks } \\
\hline \multirow[t]{2}{*}{ Strong ties (nb persons) } & 13.10 & $1.335^{*}$ & $2.305^{* * *}$ & $1.487^{*}$ & $1.824^{*}$ & 0.728 \\
\hline & $(0.107)$ & $(0.791)$ & $(0.825)$ & $(0.783)$ & $(1.067)$ & $(1.058)$ \\
\hline \multirow[t]{2}{*}{ Relatives } & 7.400 & 0.591 & $1.216^{*}$ & 0.611 & 1.096 & 0.550 \\
\hline & $(0.0866)$ & $(0.623)$ & $(0.631)$ & $(0.517)$ & $(0.728)$ & $(0.847)$ \\
\hline \multirow[t]{2}{*}{ Close friends } & 5.696 & $0.744^{*}$ & $1.090^{* *}$ & $0.875^{*}$ & 0.728 & 0.178 \\
\hline & $(0.0498)$ & $(0.414)$ & $(0.430)$ & $(0.476)$ & $(0.621)$ & $(0.548)$ \\
\hline Observations & $16^{\prime} 791$ & $16^{\prime} 791$ & $16^{\prime} 791$ & $6^{\prime} 671$ & $16^{\prime} 791$ & $11^{\prime} 532$ \\
\hline Individuals & 3'106 & 3'106 & 3'106 & $1 ’ 301$ & 3'106 & $2^{\prime} 488$ \\
\hline \multirow[t]{2}{*}{ Weak ties (nb persons) } & 10.78 & -0.706 & 0.128 & -0.160 & -0.505 & -1.929 \\
\hline & $(0.121)$ & $(1.119)$ & $(1.226)$ & $(1.400)$ & $(1.603)$ & $(1.479)$ \\
\hline \multirow[t]{2}{*}{ Neighbors } & 3.347 & -0.366 & 0.238 & 0.399 & -0.428 & -0.208 \\
\hline & $(0.0380)$ & $(0.329)$ & $(0.328)$ & $(0.342)$ & $(0.527)$ & $(0.381)$ \\
\hline \multirow[t]{2}{*}{ Colleagues } & 7.434 & -0.340 & -0.110 & -0.559 & -0.0766 & -1.720 \\
\hline & $(0.106)$ & $(0.986)$ & $(1.098)$ & $(1.271)$ & $(1.365)$ & $(1.339)$ \\
\hline Observations & $16^{\prime} 486$ & $16^{\prime} 486$ & $16^{\prime} 486$ & $6{ }^{\prime} 580$ & $16^{\prime} 486$ & $11^{\prime} 311$ \\
\hline Individuals & 3’101 & 3'101 & 3'101 & 1'295 & 3'101 & $2^{\prime} 476$ \\
\hline \multicolumn{7}{|l|}{ B. SOCIAL CAPITAL } \\
\hline \multirow[t]{2}{*}{ All clubs (active members) } & 0.862 & $-0.210^{* * *}$ & $-0.161^{* *}$ & $-0.178^{* *}$ & -0.125 & $-0.231^{* * *}$ \\
\hline & $(0.00820)$ & $(0.0683)$ & $(0.0648)$ & $(0.0698)$ & $(0.101)$ & $(0.0828)$ \\
\hline \multirow[t]{2}{*}{ Redistributive clubs } & 0.266 & $-0.108^{* * *}$ & $-0.0798^{* *}$ & -0.0222 & -0.0392 & $-0.0856^{*}$ \\
\hline & $(0.00449)$ & $(0.0360)$ & $(0.0368)$ & $(0.0389)$ & $(0.0546)$ & $(0.0443)$ \\
\hline \multirow[t]{2}{*}{ General clubs } & 0.596 & $-0.102^{* *}$ & $-0.0809^{*}$ & $-0.156^{* * *}$ & -0.0861 & $-0.145^{* *}$ \\
\hline & $(0.00574)$ & $(0.0461)$ & $(0.0446)$ & $(0.0499)$ & $(0.0707)$ & $(0.0575)$ \\
\hline Observations & $16^{\prime} 923$ & $16^{\prime} 923$ & $16^{\prime} 923$ & $6 ' 723$ & $16^{\prime} 923$ & $11^{\prime} 579$ \\
\hline Individuals & 3'119 & 3'119 & 3'119 & 1'303 & 3’119 & 2'494 \\
\hline
\end{tabular}

Notes: Standard errors in parentheses (clustered by municipality and year). ${ }^{*} p<0.10$, ** $p<0.05$, *** $p<0.01$. Estimate on Latin coefficient in regression of dependent variable on individual characteristics (age, sex, education), municipality characteristics (population, religion, foreigners, unemployment, sectoral structure, agglomeration structure, area usage, area, altitude, lake border), year and cantonal fixed effects. Strong ties: Sum of number of relatives and number of friends. Weak ties: Sum of number of neighbors and colleagues. Sums the membership of the following clubs: local or parents / syndicate / charitable organization / women / tenants rights (redistributive) and sports or leisure / culture / protection of the environment (general) with equal weighting. Separation into language regions by ethnicity, German $=$ Swiss German, Latin = Swiss French/Italian. Source: Swiss Household Panel (1999-2008). 
a majority of German Swiss thinks that working hard pays off, but this fraction is considerably smaller among Latin Swiss. In particular, a substantial fraction of Latins think that success is almost purely driven by luck and connections.

Figure 6: World Values Survey Evidence on Beliefs

a. Freedom of choice and control over the way your life turns out

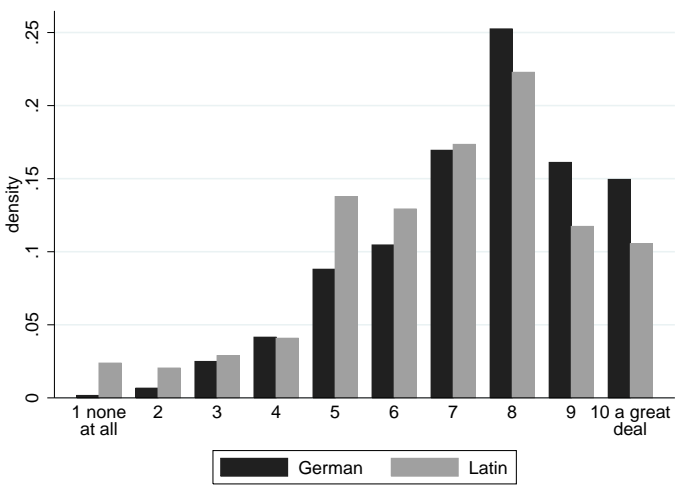

b. Success is a matter of hard work vs. success is a matter of luck and connections

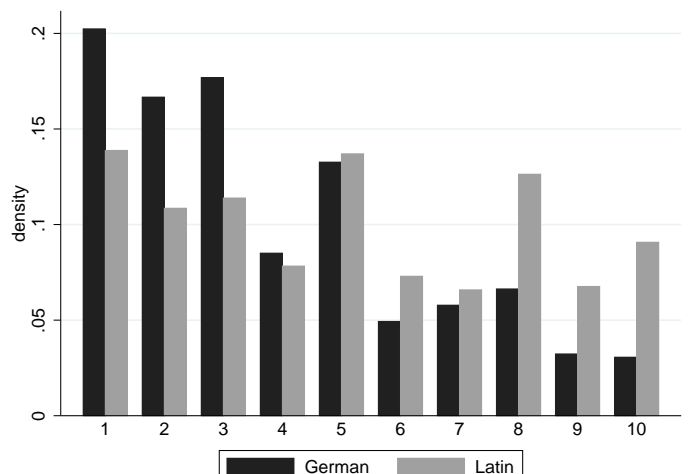

Notes: Panel a: 1= non freedom of choice and control over the way my life turns out, $10=$ a great deal of freedom of choice and control over the way my life turns out. Panel b: 1=in the long run; hard work usually brings a better life, $10=$ hard work does not generally bring success - it is more a matter of luck and connections. Separation into language regions by interview language.

Source: WVS 1996.

Table 5 reports regression analyzes of these two questions and reproduces these differences across the language regions when controlling for individual characteristics and canton fixedeffects. ${ }^{33}$ Latin-Swiss respondents are significantly less convinced that they have the freedom of choice and that they can determine the way their life turns out. Taking account for all controls, the isolated reduction in freedom/control score is 0.56 among the Latin Swiss. The contrast is even stronger for the question more directly related to the "belief in a just world". When asked whether hard work pays off or whether success is a matter of luck and connection, Latin Swiss have a luck/connection score that is 1.20 points higher. These results suggest that beliefs diverge profoundly in a situation with identical actual level of social insurance - clear empirical evidence of ideology.

Where do these different views and ideology come from? An important argument is that the Latin Swiss were the minority for centuries, suppressed by the elites of Berne and the aristocracy of Fribourg. Being a suppressed minority may have contributed to the adoption of values which are based less strongly on the belief in a "just world". In contrast, repeated experience of suppression is likely to foster the belief that one's own fortune is more driven by status and ancestry than the belief that hard work bring success.

Yet there is a key problem with this explanation. In the model discussed by Bénabou and Tirole (2006) there is a feedback mechanism. Actual differences in social insurance coverage

\footnotetext{
${ }^{33}$ Regression is a simple tool to understand how membership of a language group shifts the cumulative density function in Figure 6a and b. Ordered probit analyzes are consistent with the simple regression analysis reported in Table 5.
} 
Table 5: Culture and Beliefs

\begin{tabular}{|c|c|c|c|c|c|c|}
\hline & \multirow[b]{2}{*}{ question } & \multirow{2}{*}{$\begin{array}{l}\text { number of } \\
\text { respondents }\end{array}$} & \multicolumn{3}{|c|}{ mean answer ${ }^{\dagger}$} & \multirow{2}{*}{$\begin{array}{l}\text { Coeff. } \\
\qquad \text { Latin }^{\ddagger}\end{array}$} \\
\hline & & & Latin & German & difference & \\
\hline (1) & $\begin{array}{l}\text { Freedom of choice and control } \\
\text { over the way your life turns } \\
\text { out }\end{array}$ & 1,190 & $\begin{array}{c}6.833 \\
(0.087)\end{array}$ & $\begin{array}{c}7.475 \\
(0.076)\end{array}$ & $\begin{array}{l}-0.642 \\
(0.116) * * *\end{array}$ & $\begin{array}{l}-0.560 \\
(0.116) * * *\end{array}$ \\
\hline (2) & $\begin{array}{l}\text { Success is due to hard work } \\
\text { (1) vs a matter of luck and } \\
\text { connections (10) }\end{array}$ & 1,150 & $\begin{array}{c}5.028 \\
(0.126)\end{array}$ & $\begin{array}{c}3.898 \\
(0.105)\end{array}$ & $\begin{array}{l}1.130 \\
(0.164) * * *\end{array}$ & $\begin{array}{c}1.201 \\
(0.162) * * *\end{array}$ \\
\hline
\end{tabular}

Notes: Standard errors in parentheses. ${ }^{*} p<0.10,{ }^{* *} p<0.05,{ }^{* * *} p<0.01{ }^{\dagger}$ Table entries are the mean response in the scale from 1 to 10 for both items. ${ }^{\ddagger}$ Estimate on Latin coefficient in regression of response to survey item on a full set of canton dummies, age, sex, education (low, medium, high). Separation into language regions by ethnicity, German $=$ Swiss German, Latin $=$ Swiss French/Italian. Questions are from the World Values Survey carried out in 1996.

reinforce diverging beliefs on the payoff to hard work. This feedback mechanism is missing in our setting. Actual levels of social insurance are identical on either side of the language border. Can media exposure provide the missing reinforcement link?

\subsection{Media exposure}

Arguably, public media play an even more important role in the formation of opinions and beliefs in modern societies. ${ }^{34}$ Does media exposure differ across language regions? Table 6 shows that the market for newspapers is almost completely segregated between the two language regions. ${ }^{35}$ Among the four major newspapers in the French-speaking part of the country - Le Matin, 24 heures, Tribune de Geneve, Le Temps - three are basically not present outside the language region and only LeTemps gets some attention in the German-speaking part. Similarly, the major newspapers in the German-speaking area - Blick, Tagesanzeiger, Mittellandzeitung, Berner Zeitung and Neue Zürcher Zeitung - have a very weak exposure in the Latin-speaking.

The situation is quite similar for exposure to radio and TV channels. Publica Data AG (2009) publishes market share for TV channels on a regular basis. In each language region of the country there are two public TV channels (TSR1 and TSR2 in French-speaking part, TSI1 and TSI2 in Ticino, and SF1 and SF2 in the German speaking part). However, there is little coordination and overlap in broadcasted programs across these regions. In both language regions, the market share of the public TV channels is roughly 30 percent. Looking at market shares, the overlap in common TV channels across language regions is almost zero. In the French-speaking part, the remaining channels are dominated by 4 major channels of France (TF1, M6, F2, F3) and in the

\footnotetext{
${ }^{34}$ de Tocqueville (1899) states

I am far from denying that newspapers in democratic countries lead citizens to do very ill-considered things in common; but without newspapers there would be hardly any common action at all. So they mend many more ills than they cause.

${ }^{35}$ Note also, that Swiss German journals seem to be slightly more conservative than Latin journals.
} 
Table 6: Language segregation of journals in Switzerland

\begin{tabular}{lccc}
\hline & $(1)$ & $(2)$ & $(3)$ \\
Newspaper & political tendency & Readers & Latin Readers (\%) \\
A. Swiss-LATiN & & & \\
Le Matin & independent & 283,000 & 100 \\
24 heures & independent & 230,000 & 100 \\
Tribune de Geneve & independent & 150,000 & 100 \\
Le Temps & independent & 123,000 & 77 \\
Corriere del Ticino & independent & 118,000 & 100 \\
B. Swiss-GERMAN & & & \\
Blick & independent & 650,000 & 7 \\
Tages-Anzeiger & independent & 487,000 & 0 \\
Mittelland Zeitung & liberal-independent & 459,000 & 0 \\
Berner Zeitung & independent & 398,000 & 1 \\
Neue Zürcher Zeitung & liberal & 291,000 & 5 \\
\hline
\end{tabular}

Notes: All newspapers are published daily on workdays. List shows the five most read newspaper in the Latin and the Swiss-German region. Data on political tendency from www.printmedia.ch. Data on number of readers and \% Latin readers from WEMF 2008.

Italian-speaking part, by 4 major channels of Italy (CAN5, RAI1, ITAL1, RAI2). In both subregions, these foreign channels comprise a market share of more than 40 percent. The situation is quite different in the German-speaking area where the market not captured by public TV is much more spread out across other channels (private German-Swiss and foreign channels). The four major TV channels of Germany (ARD, ZDF, SAT1, RTL) are less dominant with a market share of not more than 20 percent. This is consistent with the claim that Latin-speaking Switzerland is more exposed to its large neighbor speaking the same language - France and Italy - whereas German-speaking Switzerland has much weaker ties to its large neighbor speaking the same language. ${ }^{36}$

We conclude that media are strongly segmented across Swiss language groups. As a result communication on important political issues, including social insurance and redistribution, is limited. Given the important role of media on the formation of opinions and beliefs, convergence in these opinions and beliefs across language groups is therefore more limited than in an environment with integrated media. As a result, the high degree of media segmentation is likely to increase the persistence in different beliefs and values across language areas in general and in the support for redistributive social insurance in particular. ${ }^{37}$

\footnotetext{
${ }^{36}$ There is clear voting evidence on this. While the Latin-Swiss overwhelmingly supported joining the European Economic Area in 1992, the German-Swiss were much more reluctant to enter the EEA. The main reason for joining the EEA in the Latin-speaking area was to reinforce economic but also cultural links with its large European neighbors France and Italy. The German-speaking area focused only on economic links. There was no enthusiasm to entertain tighter links with Germany.

${ }^{37}$ The rift in beliefs may be amplified by media bias, i.e. the tendency of newspapers to report on the same issue in different ways. Groseclose and Milyo (2005) provide evidence of media bias in the US. DellaVigna and Kaplan (2007) find strong evidence of media bias affecting voting results.
} 


\section{Conclusions}

In this paper, we have investigated the role of whether culture has an important impact on the demand for government-provided social insurance. Government-provided social insurance programmes are hotly debated in all countries and they use up a large fraction of governments' budget. Yet the way that these programmes are implemented differs widely across countries. In this paper we look at Switzerland, a country that is well known for its cultural diversity and its particular political institutions. We exploit the fact that Switzerland is divided into two broad cultural groups on the basis of language: the German Swiss, known for their commitment to work hard, to be punctual, and to focus on individual responsibility; and Latin Swiss, the historically suppressed minority, who tend to rely much more on the role of the state and favor income redistribution. Apart from its cultural diversity, Switzerland has a strong tradition of direct democracy. Voting data from national referenda provide us with a measure of the demand for social insurance of the various cultural groups.

To isolate an impact of culture from other potential determinants of the demand for social insurance, we focus on changes in culture within a narrowly defined geographic area. We exploit the fact that the language border within Switzerland is a clear geographic border. Within a distance of 5 kilometers, the fraction of Latin-speaking Swiss residents falls from more than 90 percent to less than 5 percent (and vice versa for German native speakers). The border is no geographical barrier. Moreover, since parts of the language border runs through cantons, and since we include canton fixed effects, we control for the institutional environment. This allows us to adopt a spatial regression discontinuity design to separate the impact of culture from the impact of other potential determinants of the demand for social insurance. Large parts of the language border runs within Swiss states (cantons). This is important since most policies in Switzerland are set at the cantonal (rather than the federal) level. Hence local contrasts on either side of the border measure language-group differences in the demand for social insurance even if they face identical levels of actual insurance.

We provide empirical evidence on the demand for four social insurance programmes that cover the most important risks that individuals face over their lifetimes (i) old age insurance, (ii) maternity insurance, (iii) unemployment insurance and (iv) health insurance. We study a wide range of voting results from national referenda all of which were related to major changes (introductions and/reforms) of these social insurance programmes. For referenda related to (reforms of) old-age insurance and (the introduction of) maternity insurance, our estimates suggest that the demand for social insurance (as measured by voting results) is up to 10 percentage points higher among the Latin-Swiss population than among the German-Swiss population. We also find consistently higher (lower) support for more generous (restrictive) unemployment and health insurance regulations among the Latin-Swiss than among the German-Swiss population.

To shed light on possible reasons for the increased demand for government-provided social insurance by the Latin-speaking citizens, we investigated three possible channels: social networks, ideology, and media exposure. We find that social networks are unlikely to explain the major part of differences in support for social insurance in Latin-speaking Switzerland. In fact, Latin speakers have even somewhat closer ties to the family and close friends, but have somewhat weaker ties to colleagues and are less engaged in clubs. We find evidence that Latin speakers 
believe less than German speakers that hard work pays off and they feel they have less freedom and control over their lives. This is consistent with an ideological predisposition that favors redistribution. A deeper reason for such ideological differences may be historical. Latin Swiss have been the oppressed minority for centuries and repeated experience of suppression may have fostered weaker beliefs in a "just world". Finally, we have documented the strong segmentation media markets by language regions. The lack of social communication via media on important political issues such as the introduction and/or reform of social insurance programs can explain the lack of convergence in beliefs among social groups that live under similar institutional arrangements.

Clearly, divergence of collective beliefs does not affect voting outcomes as long as the median voter is from the same social group. For instance, Swiss national votes are by and large determined by the collective belief of the dominant majority language group, which is German. Yet, divergent beliefs may have important efficiency consequences. Pessimism may discourage labor supply, change health prevention strategies, and affect savings and consumption behavior. Understanding the consequences of divergent beliefs on these economic decisions appears a worthwhile topic of future research.

\section{References}

Alesina, A. and Angeletos, G.-M. (2005). Fairness and Redistribution. American Economic Review, 95(4), 960-980.

Alesina, A. and Fuchs-Schündeln, N. (2007). Goodbye lenin (or not?): The effect of communism on people. American Economic Review, 97(4), 1507-1528.

Alesina, A. and Glaeser, E. (2004). Fighting Poverty in the US and Europe. Oxford University Press.

Alesina, A. F. and Giuliano, P. (2009). Preferences for Redistribution. Working paper 14825, NBER.

Algan, Y. and Cahuc, P. (2009). Civic Virtue and Labor Market Institutions. American Economic Journal: Macroeconomics, 11(1), 111-145.

Angelucci, M., DeGiorgi, G., Rangel, M. A., and Rasul, I. (2009). Family networks and school enrolment: Evidence from a randomized social experiment. Discussion paper 4497, IZA.

Aspachs-Bracons, O., Clots-Figueras, I., and Masella, P. (2007). Identity and Language Policies. Working paper no 07-77, Universidad Carlos III de Madrid.

Bëhi, C. (2000). Röstigraben. NZZ Press.

Bénabou, R. and Ok, E. A. (2001). Social mobility and the demand for redistribution: The poum hypothesis. Quarterly Journal of Economics, 116(2), 447-487.

Bénabou, R. and Tirole, J. (2006). Belief in a just world and redistributive politics. Quarterly Journal of Economics, 121(2), 699-746. 
Bisin, A. and Verdier, T. (2000). A model of cultural transmission, voting and political ideology. European Journal of Political Economy, 16(1), 5-29.

Björklund, A., Lindahl, M., and Plug, E. (2006). The origins of intergenerational associations: Lessons from swedish adoption data. The Quarterly Journal of Economics, 121(3), 999-1028.

Bloch, F., Genicot, G., and Ray, D. (2008). Informal insurance in social networks. Journal of Economic Theory, 143, 36-58.

Bonoli, G. and Häusermann, S. (2009). New socio-structural conflicts in social policy issues: evidence from swiss referendum votes. European Societies, 11(2), 211-232.

Bowles, S. (1998). Endogenous Preferences: The Cultural Consequences of Markets and Other Economic Institutions. Journal of Economic Literature, 26, 75-111.

Bowles, S. and Polanía Reyes, S. (2009). Economic incentives and social preferences: A preference-based lucas critique of public policy. Mimeo, Santa Fe Institute and University of Siena.

Boyd, R. and Richerson, P. J. (1985). Culture and the Evolutionary Process. Chicago: University of Chicago Press.

Burke, M. A. and Young, H. P. (2010). Social norms. In A. Bisin, J. Benhabib, and M. Jackson, editors, Handbook of Social Economics, page forthcoming. North Holland: Amsterdam.

Card, D. E. and Lee, D. S. (2008). Regression Discontinuity Inference with Specification Error. Journal of Econometrics, 142(2), 655-674.

Carter, M. R. and Castillo, M. (2004). Morals, Markets and Mutual Insurance: Using Economic Experiments to Study Recovery from Hurricane Mitch. Mimeo, University of WisconsinMadison.

Clark, A. E. (2003). Unemployment as a Social Norm: Psychological Evidence from Panel Data. Journal of Labor Economics, 21(2), 289-322.

Corneo, G. (2001). Inequality and the State: Comparing US and German Preferences. Annales d'Economie et de Statistique, (63/64), 283-296.

de Tocqueville, A. (1899). Democracy in America. Vol I (translated by Henry Reeve). Colonial Press, New York.

DellaVigna, S. and Kaplan, E. (2007). The fox news effect: Media bias and voting. Quarterly Journal of Economics, 122(3), 1187-1234.

Durlauf, S. N. and Fafchamps, M. (2005a). Social capital. In P. Aghion and S. Durlauf, editors, Handbook of Economic Growth, volume 1 of Handbook of Economic Growth, chapter 26, pages 1639-1699. Elsevier.

Durlauf, S. N. and Fafchamps, M. (2005b). Social Capital. In P. Aghion and S. Durlauf, editors, Handbook of Economic Growth, pages 1639-1699. Elsevier. 
Fafchamps, M. and Lund, S. (2003). Risk-sharing networks in rural Philippines. Journal of Development Economics, 71, 261-287.

Fong, C. M. (2001). Social Preferences, Self-Interest, and the Demand for Redistribution. Journal of Public Economics, 82(2), 225-246.

Granovetter, M. (1973). The Strength of Weak Ties. American Journal of Sociology, 78, 13601380.

Groseclose, T. and Milyo, J. (2005). A measure of media bias*. Quarterly Journal of Economics, 120(4), 1191-1237.

Guiso, L., Sapienza, P., and Zingales, L. (2006). Does Culture affect Economic Outcomes? Journal of Economic Perspectives, 20(2), 23-48.

Hahn, J., Todd, P., and van der Klaauw, W. (2001). Identification and Estimation of Treatment Effects with a Regression-Discontinuity Design. Econometrica, 69(1), 201-209.

Holland, P. W. (1986). Statistics and Causal Inference. Journal of the American Statistical Association, 81(396), 945-960.

Imbens, G. W. and Angrist, J. D. (1994). Identification and Estimation of Local Average Treatment Effects. Econometrica, 62(2), 467-475.

Imbens, G. W. and Kalyanaraman, K. (2009). Optimal bandwidth choice for the regression discontinuity estimator. IZA Discussion Papers 3995, Institute for the Study of Labor (IZA).

Imbens, G. W. and Wooldridge, J. M. (2009). Recent developments in the econometrics of program evaluation. Journal of Economic Literature, 47(1), 5-86.

Lalive, R. (2008). How do Extended Benefits Affect Unemployment Duration? A Regression Discontinuity Approach. Journal of Econometrics, 142(2), 785-806.

Lee, D. and Lemieux, T. (2009). Regression discontinuity designs in economics. Working Papers 1118, Princeton University, Department of Economics, Industrial Relations Section.

Leonardi, R., Nannetti, R., and Putnam, R. (1993). Making Democracy Work: Civic Traditions in Modern Italy. Princeton: Princeton University Press.

Lüdi, G. and Werlen, I. (2005). Sprachenlandschaft in der Schweiz, Eidgenössische Volkszählung 2000. Technical report, Bundesamt für Statistik, Neuchatel.

Luttmer, E. F. and Singhal, M. (2008). Culture, Context, and the Taste for Redistribution. Working Paper 14268, NBER.

Narayan, D. and Pritchett, L. (1999). Cents and Sociability: Household Income and Social Capital in Rural Tanzania. Economic Development and Cultural Change, 47(4), 871-897.

Novembre, J., Johnson, T., Bryc, K., Kutalik, Z., Boyko, A. R., Auton, A., Indap, A., King, K. S., Bergmann, S., Nelson, M. R., Stephens, M., and Bustamante, C. D. (2008). Genes mirror geography within Europe. Nature, 456, 98-101. 
Piketty, T. (1995). Social mobility and redistributive politics. Quarterly Journal of Economics, 110(3), 551-584.

Putnam, R. (2000). Bowling Alone: The Collapse and Revival of American Community. New York: Simon and Schuster.

Putnam, R. D. (2001). Bowling Alone: The Collapse and Revival of American Community. Simon \& Schuster.

Steinhauer, A. (2010). Labor force participation and working time: How culture affects female labor supply in switzerland. Mimeo, University of Zurich.

Stutzer, A. and Lalive, R. (2004). The Role of Social Norms in Job Searching and Subjective Well-Being. Journal of the European Economic Association, 2(4), 696-719.

Trépanier, C. (1991). The cajunization of french louisiana: forging a regional identity. The Geographic Journal, 157(2), 161-171.

Udry, C. (1994). Risk and Insurance in a Rural Credit Market: An Empirical Investigation in Northern Nigeria. Review of Economic Studies, 61(3), 495-526.

Verme, P. (2009). Happiness, freedom and control. Journal of Economic Behavior $\mathcal{G}$ Organization, 71(2), 146-161.

Werlen, I. (2008). Sprachkompetenzen der erwachsenen Bevölkerung in der Schweiz. Technical report, Swiss National Research Project 56.

Young, H. P. and Burke, M. A. (2001). Competition and custom in economic contracts: A case study of illinois agriculture. American Economic Review, 91(3), 559-573. 


\section{Appendix}

This appendix discusses the key identifying assumptions and empirical evidence allowing to assess the validity of these assumptions.

Let $D_{l}$ denote language group membership of individuals residing in the Swiss German territory, and $D_{r}$ is language group membership of individuals residing in the Swiss Latin territory. This notation serves to introduce four types of individuals.

- Language region compliers with $D_{r}=1$ and $D_{l}=0$. These individuals are members of the Swiss Latin group if they live in Swiss Latin territory, and members of the Swiss German group if they live in Swiss German territory.

- Never-Latin speakers with $D_{r}=0$ and $D_{l}=0$. These individuals are members of the Swiss German language group regardless of their residence.

- Always-Latin speakers with $D_{r}=1$ and $D_{l}=1$. These individuals are members of the Swiss Latin language group regardless of their residence.

- Language region defiers with $D_{r}=0$ and $D_{l}=1$. These individuals are members of the Swiss German group if they live in Swiss Latin territory, and members of the Swiss Latin group if they live in Swiss German territory.

Identification requires three key assumptions.

1. $D_{r} \geq D_{l}$, i.e. individual language group membership changes monotonically with residence.

2. The limit shares of the remaining types are identical on either side of the language border, i.e. $\operatorname{Prob}^{l}\left(D_{r}=1, D_{l}=0\right)=\operatorname{Prob}^{r}\left(D_{r}=1, D_{l}=0\right)$ and $\operatorname{Prob}^{l}\left(D_{r}=0, D_{l}=0\right)=$ $\operatorname{Prob}^{r}\left(D_{r}=0, D_{l}=0\right)$ and $\operatorname{Prob}^{l}\left(D_{r}=1, D_{l}=1\right)=\operatorname{Prob}^{r}\left(D_{r}=1, D_{l}=1\right)$.

3. The limit mean potential outcomes are balanced for each of these three types, i.e. for compliers $E^{l}\left(Y_{0} \mid D_{r}=1, D_{l}=0\right)=E^{r}\left(Y_{0} \mid D_{r}=1, D_{l}=0\right)$ and $E^{l}\left(Y_{1} \mid D_{r}=1, D_{l}=0\right)=$ $E^{r}\left(Y_{1} \mid D_{r}=1, D_{l}=0\right)$, for never-takers $E^{l}\left(Y_{0} \mid D_{r}=0, D_{l}=0\right)=E^{r}\left(Y_{0} \mid D_{r}=0, D_{l}=0\right)$, for always-takers $E^{l}\left(Y_{1} \mid D_{r}=1, D_{l}=1\right)=E^{r}\left(Y_{1} \mid D_{r}=1, D_{l}=1\right)$.

Are the three identifying assumptions satisfied? Understanding the first assumption boils down to understanding language group membership. Residents of language border towns are members of the Swiss Latin group if they have Swiss Latin speaking parents (vertical transmission of language) or if they chose to adopt one of the three Swiss Latin languages later in their life (horizontal transmission of language). Vertical transmission is directly consistent with monotonicity since Swiss Latin parents will be more likely to reside in Swiss Latin territory than vice versa. Horizontal transmission likely reinforces monotonicity since people tend to adopt the majority language later in their life.

The second and third assumption boil down to conditional independence of outcome and potential language group membership at the language border. While conditional independence 
can not be tested directly, we report the key indirect test (following the suggestions by Lee and Lemieux (2009)) that consists of checking the balance of covariates at the language border.

Table 7 discusses local contrasts in culture, composition, and geography. The unit of observation is a municipality. All results are un-weighted. Column (1) reports the mean of a characteristic in the Latin region, column (2) reports the corresponding mean in the Swiss German region, column (3) reports the contrast Swiss Latin vs Swiss German municipalities, column (4) provides an estimate of the local contrast (using regression 1 with each member of the vector $X_{j}$ as a dependent variable (and without further municipality controls but with canton dummies), and column (5) provides an estimate of the local contrast with cubic spatial trends (allowed to differ on either side of the border).

Panel A in Table 7 contrasts language group membership and religious group membership at the border. Row 1 shows that across all municipalities, the share Swiss Latin speakers is $87 \%$ in Swiss Latin municipalities, $3 \%$ in Swiss German municipalities, the difference amounting to 84 percentage points. At the border, the share Swiss Latin speakers increases by anywhere from 70 $\%$ (column 5) to $75 \%$ (column 4). This means Language group membership increases strongly. Rows 2 and 3 indicate that there is a corresponding, but much weaker, change in religious group membership at the language border. Swiss Latin border towns are characterized by between 11 and 14 percentage points fewer protestants, compensated by a 5 to 12 higher share of catholics (the remaining and excluded religions making up for the difference). In all our results below we control for religious group membership to disentangle the role of religious group membership from language group membership.

Panel B in Table 7 contrasts socio-demographic characteristics of residents at the language border. All information is from the most recent year 2000 census. Results indicate that the age structure is perfectly balanced at the language border (rows 1 and 2). There is a slightly lower share of men living in Swiss Latin border towns (row 3). Swiss Latin border municipalities are also characterized by stronger variance in education. Both the low educated and the highly educated groups are larger in Swiss Latin municipalities than in Swiss German border towns (rows 4-6). Municipalities are inhabited by 4800 (Swiss Latin) to 5800 (Swiss German) residents. Swiss Latin border municipalities are slightly larger (5 to 16 inhabitants more) than Swiss German border towns (row 7). Swiss Latin border municipalities host a higher share of immigrants than Swiss German border municipalities (6 to 9 percentage points more; row 8).

Panel $\mathrm{C}$ in Table 8 reports differences in geography. The geography controls include information on whether a municipality is located in a larger agglomeration, or whether the municipality is characterized by a large tourism sector. We also measure a municipality's altitude (in meters above sea level), access to a lake border, and the use structure of its area. While there are some significant differences between border towns (especially for the baseline specification in column 4), none of these differences appears to be robust to including cubic terms in spatial distance. This means that we are not very far from a situation of balanced geographic background of border municipalities. 
Table 7: How do Border Towns Compare in Terms of Culture, Composition and Geography?

\begin{tabular}{|c|c|c|c|c|c|}
\hline & $(1)$ & $(2)$ & $(3)$ & $(4)$ & (5) \\
\hline Distance & $\begin{array}{l}\text { Mean } \\
\text { Latin } \\
\text { no }\end{array}$ & $\begin{array}{c}\text { Mean } \\
\text { German } \\
\text { no }\end{array}$ & $\begin{array}{c}\text { Difference } \\
\text { All } \\
\text { no }\end{array}$ & $\begin{array}{l}\text { Difference } \\
50 \mathrm{~km} \\
\text { quadratic }\end{array}$ & $\begin{array}{c}\text { Difference } \\
50 \mathrm{~km} \\
\text { cubic }\end{array}$ \\
\hline$\%$ Latin speaking & $\begin{array}{l}87.25 \\
{[7.336]}\end{array}$ & $\begin{array}{l}3.239 \\
{[3.708]}\end{array}$ & $\begin{array}{c}84.01^{* * *} * \\
{[0.447]}\end{array}$ & $\begin{array}{c}75.35^{* * *} \\
{[2.775]}\end{array}$ & $\begin{array}{c}69.99^{* * *} \\
{[4.150]}\end{array}$ \\
\hline \multicolumn{6}{|l|}{ A. RELigion } \\
\hline$\%$ protestants & $\begin{array}{c}30.27 \\
{[21.59]}\end{array}$ & $\begin{array}{c}41.38 \\
{[23.35]}\end{array}$ & $\begin{array}{c}-11.10^{* * *} \\
{[1.544]}\end{array}$ & $\begin{array}{c}-10.89^{* *} \\
{[5.258]}\end{array}$ & $\begin{array}{c}-14.09^{*} \\
{[8.297]}\end{array}$ \\
\hline \% catholics & $\begin{array}{c}49.18 \\
{[24.93]}\end{array}$ & $\begin{array}{c}41.30 \\
{[23.77]}\end{array}$ & $\begin{array}{c}7.881^{* * *} \\
{[1.712]}\end{array}$ & $\begin{array}{c}4.583 \\
{[6.420]}\end{array}$ & $\begin{array}{c}12.55 \\
{[9.802]}\end{array}$ \\
\hline \multicolumn{6}{|c|}{ B. Socio-Demographic Composition } \\
\hline Age: 60 plus & $\begin{array}{c}0.285 \\
{[0.070]}\end{array}$ & $\begin{array}{c}0.267 \\
{[0.054]}\end{array}$ & $\begin{array}{c}0.022^{* * *} \\
{[0.003]}\end{array}$ & $\begin{array}{c}-0.017^{*} \\
{[0.009]}\end{array}$ & $\begin{array}{l}-0.017 \\
{[0.013]}\end{array}$ \\
\hline Age: $35-59$ & $\begin{array}{c}0.469 \\
{[0.053]}\end{array}$ & $\begin{array}{c}0.478 \\
{[0.0 .045]}\end{array}$ & $\begin{array}{c}-0.009^{* * *} \\
{[0.002]}\end{array}$ & $\begin{array}{c}0.002 \\
{[0.008]}\end{array}$ & $\begin{array}{c}0.007 \\
{[0.011]}\end{array}$ \\
\hline Male & $\begin{array}{c}0.483 \\
{[0.029]}\end{array}$ & $\begin{array}{c}0.493 \\
{[0.022]}\end{array}$ & $\begin{array}{c}-0.011^{* * *} \\
{[0.001]}\end{array}$ & $\begin{array}{l}-0.010 \\
{[0.007]}\end{array}$ & $\begin{array}{l}-0.025^{*} \\
{[0.013]}\end{array}$ \\
\hline Educ. secondary 1 & $\begin{array}{c}0.488 \\
{[0.061]}\end{array}$ & $\begin{array}{c}0.532 \\
{[0.055]}\end{array}$ & $\begin{array}{c}-0.044^{* * *} \\
{[0.002]}\end{array}$ & $\begin{array}{c}0.004 \\
{[0.011]}\end{array}$ & $\begin{array}{c}0.022 \\
{[0.017]}\end{array}$ \\
\hline Educ. secondary 2 & $\begin{array}{c}0.280 \\
{[0.090]}\end{array}$ & $\begin{array}{c}0.248 \\
{[0.077]}\end{array}$ & $\begin{array}{c}0.032^{* * *} \\
{[0.003]}\end{array}$ & $\begin{array}{c}-0.041^{* *} \\
{[0.019]}\end{array}$ & $\begin{array}{c}-0.066^{* *} \\
{[0.030]}\end{array}$ \\
\hline Educ. tertiary & $\begin{array}{c}0.155 \\
{[0.072]}\end{array}$ & $\begin{array}{c}0.144 \\
{[0.054]}\end{array}$ & $\begin{array}{c}0.011^{* * *} \\
{[0.003]}\end{array}$ & $\begin{array}{c}0.031^{* * *} \\
{[0.012]}\end{array}$ & $\begin{array}{l}0.029^{*} \\
{[0.017]}\end{array}$ \\
\hline Population & $\begin{array}{c}4,796 \\
{[13,229]}\end{array}$ & $\begin{array}{c}5,781 \\
{[16,713]}\end{array}$ & $\begin{array}{l}-984.1 \\
{[1,005]}\end{array}$ & $\begin{array}{l}5,460^{*} \\
{[3,283]}\end{array}$ & $\begin{array}{c}15,785^{* *} \\
{[7,902]}\end{array}$ \\
\hline$\%$ foreigners & $\begin{array}{c}18.70 \\
{[10.53]}\end{array}$ & $\begin{array}{c}13.98 \\
{[8.428]}\end{array}$ & $\begin{array}{c}4.727^{* * *} \\
{[0.691]}\end{array}$ & $\begin{array}{c}8.775^{* *} \\
{[3.480]}\end{array}$ & $\begin{array}{l}5.994 \\
{[5.071]}\end{array}$ \\
\hline
\end{tabular}


Table 8: How do Border Towns Compare in Terms of Culture, Composition and Geography? continued

\begin{tabular}{|c|c|c|c|c|c|}
\hline Distance & $\begin{array}{c}(1) \\
\text { Mean } \\
\text { Latin } \\
\text { no }\end{array}$ & $\begin{array}{c}(2) \\
\text { Mean } \\
\text { German } \\
\text { no }\end{array}$ & $\begin{array}{c}(3) \\
\text { Difference } \\
\text { All } \\
\text { no }\end{array}$ & $\begin{array}{c}(4) \\
\text { Difference } \\
50 \mathrm{~km} \\
\text { quadratic }\end{array}$ & $\begin{array}{c}(5) \\
\text { Difference } \\
50 \mathrm{~km} \\
\text { cubic }\end{array}$ \\
\hline \multicolumn{6}{|l|}{ C. Geography } \\
\hline Agglomeration & $\begin{array}{c}0.558 \\
{[0.497]}\end{array}$ & $\begin{array}{c}0.521 \\
{[0.500]}\end{array}$ & $\begin{array}{c}0.0374 \\
{[0.0347]}\end{array}$ & $\begin{array}{c}0.432^{* *} \\
{[0.214]}\end{array}$ & $\begin{array}{c}0.165 \\
{[0.299]}\end{array}$ \\
\hline Touristy & $\begin{array}{l}0.0498 \\
{[0.218]}\end{array}$ & $\begin{array}{l}0.0338 \\
{[0.181]}\end{array}$ & $\begin{array}{c}0.0160 \\
{[0.0144]}\end{array}$ & $\begin{array}{l}-0.0766 \\
{[0.0808]}\end{array}$ & $\begin{array}{l}0.0513 \\
{[0.107]}\end{array}$ \\
\hline Altitude (m) & $\begin{array}{c}574.6 \\
{[227.8]}\end{array}$ & $\begin{array}{c}530.8 \\
{[217.5]}\end{array}$ & $\begin{array}{c}43.81^{* * *} * \\
{[15.65]}\end{array}$ & $\begin{array}{l}-159.1 \\
{[106.1]}\end{array}$ & $\begin{array}{c}190.2 \\
{[127.2]}\end{array}$ \\
\hline$\%$ area: arboricultural & $\begin{array}{c}4.546 \\
{[7.962]}\end{array}$ & $\begin{array}{c}2.825 \\
{[3.199]}\end{array}$ & $\begin{array}{c}1.721^{* * *} \\
{[0.476]}\end{array}$ & $\begin{array}{c}2.222 \\
{[2.543]}\end{array}$ & $\begin{array}{l}-1.109 \\
{[3.152]}\end{array}$ \\
\hline$\%$ area: agriculture & $\begin{array}{c}31.16 \\
{[24.10]}\end{array}$ & $\begin{array}{c}41.24 \\
{[18.03]}\end{array}$ & $\begin{array}{c}-10.09^{* * *} \\
{[1.558]}\end{array}$ & $\begin{array}{c}-18.03^{* *} \\
{[7.141]}\end{array}$ & $\begin{array}{l}-9.035 \\
{[9.762]}\end{array}$ \\
\hline$\%$ area: alp & $\begin{array}{c}6.264 \\
{[10.55]}\end{array}$ & $\begin{array}{c}3.190 \\
{[8.237]}\end{array}$ & $\begin{array}{c}3.074^{* * *} \\
{[0.688]}\end{array}$ & $\begin{array}{c}1.361 \\
{[4.090]}\end{array}$ & $\begin{array}{c}5.408 \\
{[4.338]}\end{array}$ \\
\hline$\%$ area: forest & $\begin{array}{c}30.70 \\
{[20.98]}\end{array}$ & $\begin{array}{c}30.28 \\
{[12.88]}\end{array}$ & $\begin{array}{c}0.417 \\
{[1.310]}\end{array}$ & $\begin{array}{l}-4.659 \\
{[6.317]}\end{array}$ & $\begin{array}{l}-4.770 \\
{[7.706]}\end{array}$ \\
\hline$\%$ area: unproductive & $\begin{array}{c}5.787 \\
{[11.71]}\end{array}$ & $\begin{array}{c}4.722 \\
{[9.883]}\end{array}$ & $\begin{array}{c}1.065 \\
{[0.778]}\end{array}$ & $\begin{array}{c}1.591 \\
{[3.740]}\end{array}$ & $\begin{array}{l}-1.055 \\
{[5.218]}\end{array}$ \\
\hline$\%$ area: constructed & $\begin{array}{c}20.03 \\
{[19.37]}\end{array}$ & $\begin{array}{c}16.60 \\
{[12.29]}\end{array}$ & $\begin{array}{c}3.433^{* * *} \\
{[1.215]}\end{array}$ & $\begin{array}{c}15.35^{* * *} \\
{[5.782]}\end{array}$ & $\begin{array}{c}8.828 \\
{[7.290]}\end{array}$ \\
\hline Lake border & $\begin{array}{c}0.256 \\
{[0.437]}\end{array}$ & $\begin{array}{c}0.185 \\
{[0.388]}\end{array}$ & $\begin{array}{c}0.0712^{* *} \\
{[0.0294]}\end{array}$ & $\begin{array}{c}-0.0114 \\
{[0.208]}\end{array}$ & $\begin{array}{l}-0.138 \\
{[0.331]}\end{array}$ \\
\hline Municipalities & 1026 & 1543 & 2569 & 1177 & 1177 \\
\hline $\begin{array}{l}\text { Notes: Columns (1) and } \\
\text { standard errors in parent } \\
\text { coefficient in regression o } \\
\text { German = Swiss Germar } \\
\text { (2000) and Office Federal }\end{array}$ & 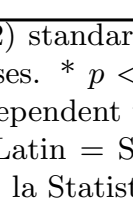 & $\Gamma$ & alian. So & olumns (3) & $\begin{array}{l}\text { (5) robust } \\
\text { e on Latin } \\
\text { ked effects. } \\
\text { hold Panel }\end{array}$ \\
\hline
\end{tabular}

